\title{
New Insight into the Nature of Shear Rupture Propagation in Pristine Rocks and Pre-Existing Faults
}

\author{
B.G. Tarasov The University of Western Australia, Australia
}

\begin{abstract}
This paper proposes a new insight into the role of fault structure in the determination of fault properties which explains a number of enigmatic aspects of fault behaviour. It is shown that hard rocks which failed at high confining pressure $\left(\sigma_{3}\right)$ exhibit specific properties that distinguish them markedly from common rock behaviour. They become extremely brittle with brittleness increasing with $\sigma_{3}$ and lose shear resistance within a certain range of shear rupture displacement. The behaviour is caused by the intrinsic nature of the fault structure, which is an echelon of blocks operating as hinges, essentially eliminating friction at high confining pressure of a certain displacement range. Such rock properties result in increasing instability with depth and make rupture abnormally violent, both of which are well-established experimentally from studies of earthquakes and rockbursts at high stress level.
\end{abstract}

The paper demonstrates that, while the same block structure may be found at a different scale in primary fractures and general faults, significantly different mechanisms are responsible for the formation of the structure in each case. A new approach is proposed for understanding fault segmentation and the role of junctions in fault propagation. It is argued that segmentation is a result of advanced triggering of new fractures that propagate both towards the current fracture and in the opposite direction. This mechanism triples the fault propagation speed. Special joining shear fractures formed at the meeting of the approaching segments help to accommodate the fault displacement and can significantly decrease the fault strength - thus contradicting the general belief that junctions represent strength barriers impeding the fault motion.

It is shown also that the specific block structure involved in pre-existing natural faults can cause repeatable fault instability. A new stick-slip mechanism based on the frictionless concept is proposed in this paper. Improved understanding of the fracture process is important for better prediction and mitigation of dynamic events such as earthquakes and rockbursts.

\section{Introduction}

Shear is the only form of rock mass rupture at depth that leads to large-scale deformations accompanied by large energy release. Spontaneous development of new ruptures (faults), and reactivation of old ones, cause earthquakes and rockbursts, but the detailed mechanics of shear rupture development is still enigmatic in many respects.

It is known that shear ruptures of any scale at a certain stage of their development have an identical (universal) structure comprising an echelon of blocks (slabs, beams) separated by tensile cracks similar to that shown in Figure 1. All existing models consider the behaviour of a similar block structure at fault displacement as a fully frictional process (Peng and Johnson, 1972; Horii and Nemat-Nasser, 1985; Cox and Scholz, 1988; Ashby and Sammis, 1990; King and Sammis, 1992; Reches and Lockner, 1994; Mandel, 2000). In accordance with the models, the fault displacement is accompanied by rotation, buckling and failure of the blocks which creates friction within the fault zone. Such behaviour is in agreement with the common understanding of the rock properties: i) as the fault develops, the cohesive strength gradually decreases down to the minimum value, which is the residual strength determined by the friction low; ii) increase in confining pressure makes rocks less brittle and increases the residual strength. 


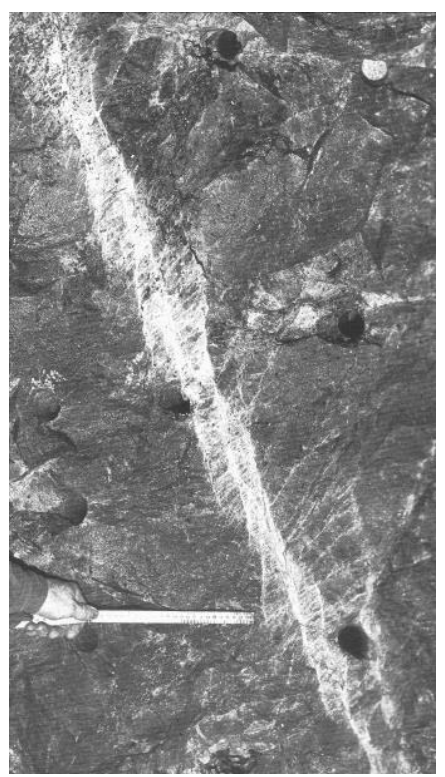

\section{Figure 1 An example of intrinsic block structure of shear ruptures (from Ortlepp, 1997)}

At the same time some aspects of spontaneous shear rupture development observed in hard rocks at great depth contradict commonly accepted rock properties which do not have unambiguous explanations at present. For example:

i) Abnormally intense rupture violence and abnormally low shear resistance of some existing faults, contradicting traditional views of residual rock strength based upon laboratory experiments.

ii) Intersonic speed of fracture propagation reported for crustal earthquakes despite high complexity and extreme damage in the rupture zone implying high energy absorption.

These questions have been studied extensively over a number of decades (for example, McKenzie and Brune, 1972; Sibson, 1980; Das, 1985; Hickman, 1991; Chester et al., 1993; Ortlepp, 1997; Rice, 2001; Scholz, 2002; Rosakis, 2002).

The present paper shows that hard rocks at high confining pressure $\left(\sigma_{3}\right)$ acquire specific properties which distinguish them markedly from common rock behaviour - they become extremely brittle with brittleness increasing with $\sigma_{3}$ and lose shear resistance within a certain range of shear rupture displacement (Tarasov and Randolph, 2007). The behaviour is caused by the fact that in hard rocks failed at high confining pressure an echelon of blocks representing the intrinsic nature of the fault structure operates as hinges, essentially eliminating friction of a certain displacement range.

The frictionless concept allows the process of shear fracture development to be viewed from a new point of view (Tarasov, 2007). A simple but well-founded classification of shear fractures is used in the paper, namely: primary and joining fractures. It is shown that despite the similarity in their structures each of which is represented by an echelon of rotating blocks, the development of these two forms of fractures is drastically different. The primary fractures propagate in a wave-like manner due to a fan-shaped self-equilibrated mechanism created on the basis of rotating blocks. The joining fractures are the result of a jump-like manner of the fault propagation due to advanced triggering mechanism. Features of the both mechanisms are analysed in the paper.

It is shown also that the specific block structure involved in pre-existing natural faults can cause the repeatable fault instability. A new stick-slip mechanism based on the frictionless concept is proposed in the paper (Tarasov, 2008). The improved understanding of the fracture process is important for better prediction and mitigation of dynamic events such as earthquakes and rockbursts.

Hard rocks of interest here are mainly magmatic and metamorphic rocks with homogeneous and fine-grained structure, for example, granite, basalt, quartzite, dolerite, diabase, etc. 


\section{Mechanism of the block structure formation}

An important breakthrough in understanding the mechanisms responsible for development of the block structure was made quite recently when acoustic emission technology and stiff servo-controlled loading systems became available (Moore et al., 1990; Lockner et al., 1991; Reches and Lockner, 1994). It was established that in hard rocks a fault nucleates by local interaction between a few micro-cracks and propagates into the unfaulted regions by inducing new micro-crack growth at its tip. Figure 2 shows the basic concept of a model by Reches and Lockner (1994) illustrating the geometry of interacting mode-I cracks, which form a shear fracture extending along a dotted line. The tensile crack orientation is along the major compressive stress. The model proposes that in the highly stressed material, the dilation of one crack can induce dilation of closely spaced neighbouring cracks that were themselves on the verge of opening. The new crack should develop in the region of maximum tension, which is located at an angle of at least $30^{\circ}$ to the existing crack (Horii and Nemat-Nasser, 1985; Lawn and Wilshaw, 1975; Pollard and Segall, 1987).

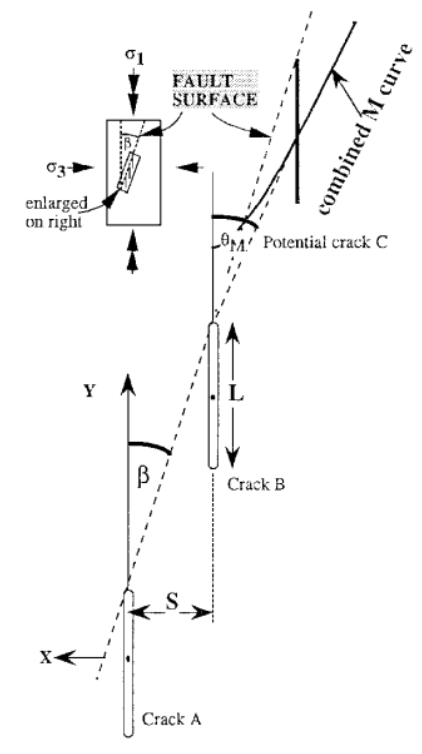

Figure 2 The geometry of three mode-I cracks forming the process zone of shear rupture (from Reches and Lockner, 1994)

An echelon of blocks (slabs, beams) separated by such tensile cracks represents a specific fault structure which is typical for shear ruptures of all scales. The fault displacement along such a structure is accompanied by rotation, buckling and failure of the blocks. This model (like all other existing models) considers this process as a fully frictional process.

\section{Concept of the frictionless shear}

\subsection{Model of the frictionless displacement}

Figure 3(a) shows an idealised model of the frictionless fault displacement where the blocks operate as hinges. Such behaviour can be realised in hard rocks failed at high confining pressure, due to i) high material strength, and ii) suitable block size (length) providing the block stability (integrity). High confining pressure suppresses the formation of long tensile cracks, so that the fault structure comprises blocks that are short enough to withstand rotation without failure. The initial orientation of the tensile cracks and the block axis coincides with the major stress $\left(\sigma_{1}\right)$. The model shows four stages of the fault displacement under the effect of shear $F$ and normal forces $N$. For simplicity, we assume that friction between rotating blocks and fracture faces is negligible and the ratio (length of block/width of block) $r / w>1$. 
The fault resistance to shear in this model is a function of the current block orientation to the fault axis (angle $\beta$ ) at their rotation. The interrelation between fault resistance $F^{\prime}$, normal reactive force $N^{\prime}$ and angle $\beta$ is shown in Figure $3 \mathrm{~b}$. Figure $3 \mathrm{c}$ demonstrates the variation of the normalised fault resistance $\left(F^{\prime} / N^{\prime}\right)$ versus angle $\beta$. The range of angle $\beta$ variation here is $\alpha \leq \beta \leq 180^{\circ}-\alpha$, where $\alpha=30^{\circ}$ is the angle of initial orientation of the tensile cracks in respect to the fault axis (as typically found for hard rocks). A dotted line on the graph represents the level of the normalised residual strength, corresponding to a coefficient of friction of 0.8 (typical for hard rocks).

(i)

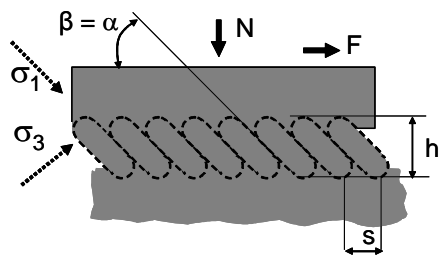

a)

(iii)

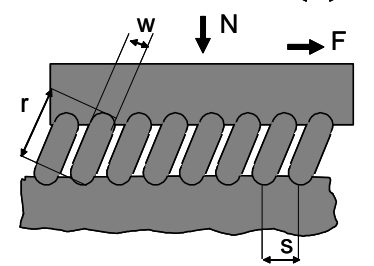

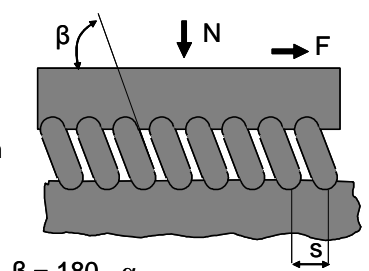

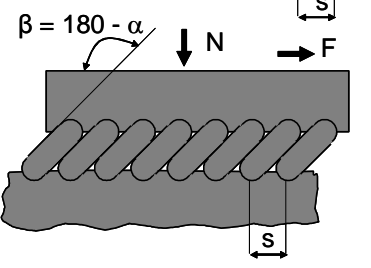

(ii)

b)

$\mathrm{F}^{\prime}$

(iv)

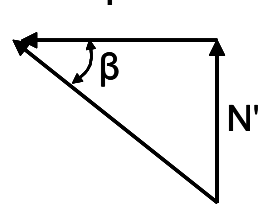

c)

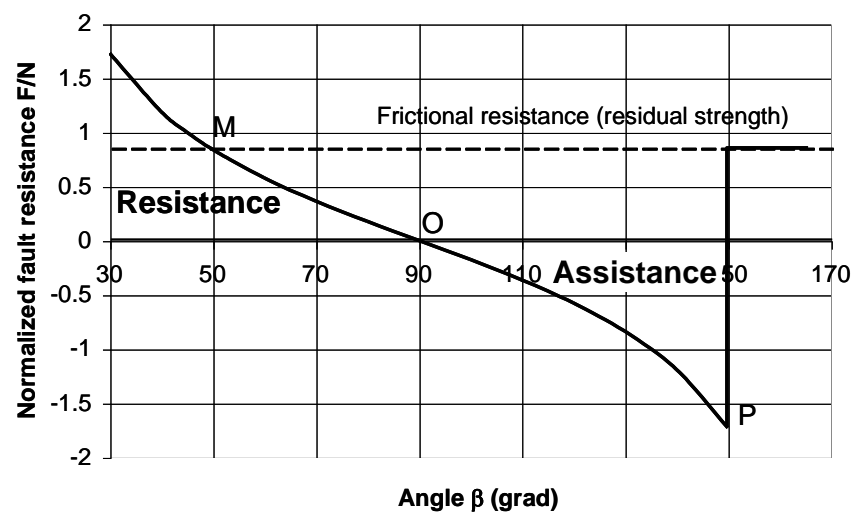

Figure 3 Idealised concept of the frictionless fault displacement (from Tarasov, 2007)

The graph shows that the fault resistance decreases with displacement, continuing past the residual frictional resistance (at point $\mathrm{M}$ ) and reaches zero resistance at point $\mathrm{O}$, where $\beta=90^{\circ}$. At $\beta>90^{\circ}$ the fault resistance becomes negative which means that at this condition the block structure under the effect of the normal force $N$ creates an active force assisting the fault displacement. We can symbolically characterise this feature as "negative friction". The greater the angle $\beta$, the greater the active force. Two parts of the graph $F^{\prime} / N^{\prime}$ versus $\beta$ lying above and below the horizontal axis indicate that the work done by the reactive $\left(F^{\prime}=F_{R}^{\prime}\right)$ and active $\left(F^{\prime}=F_{A}^{\prime}\right)$ forces within the total range of block rotation is equal to zero. When the blocks have completed their rotation at point $\mathrm{P}$ the fault structure becomes very compact again, the friction within the fault structure is restored sharply and further displacement along the fault occurs in accordance with the friction law.

It should be emphasised that at the frictionless stage of displacement (between phases I and IV) the fault resistance $F^{\prime} / N^{\prime}$ and the fault displacement $d$ are interrelated. Both of them are functions of angle $\beta$ :

$$
\begin{gathered}
\frac{F^{\prime}}{N^{\prime}}=\frac{1}{\tan \beta} \\
d=h\left(\frac{1}{\tan \alpha}-\frac{\cos \beta}{\sin \alpha}\right)
\end{gathered}
$$


Here, $h$ is the fault thickness (see Figure 3). Tarasov and Randolph (2007) give a more detailed response to this question.

\subsubsection{Instability of the frictionless structure}

Let us consider conditions of instability of the frictionless structure. Figure 4(a) shows the same fault fragment where shear force $F$ is applied through a spring. Stiffness of this loading system is characterised by line $\mathrm{CC}^{\prime}$ ' in Figure 4(b). In general, the spring stiffness may represent the elastic properties of the medium surrounding a fault including the stiffness of loading machine for laboratory conditions. Figure 4(b), graph CPLS (similar to the graph in Figure 3(c)), corresponds to the variation of fault resistance $F^{\prime}$ with displacement. The steepness of descending part (CP) of the graph characterising the stiffness of the fault structure depends on the length of rotating blocks $r$ (or fault thickness $h=r \sin \alpha$, see Figure 3(a) for explanation). On the scale of laboratory specimens the fault thickness is very small (fragments of a millimetre) which makes the fault stiffness (CP part of the graph) significantly greater than the stiffness of the surrounding medium ( $\mathrm{CC}^{\prime}$ line).

b)

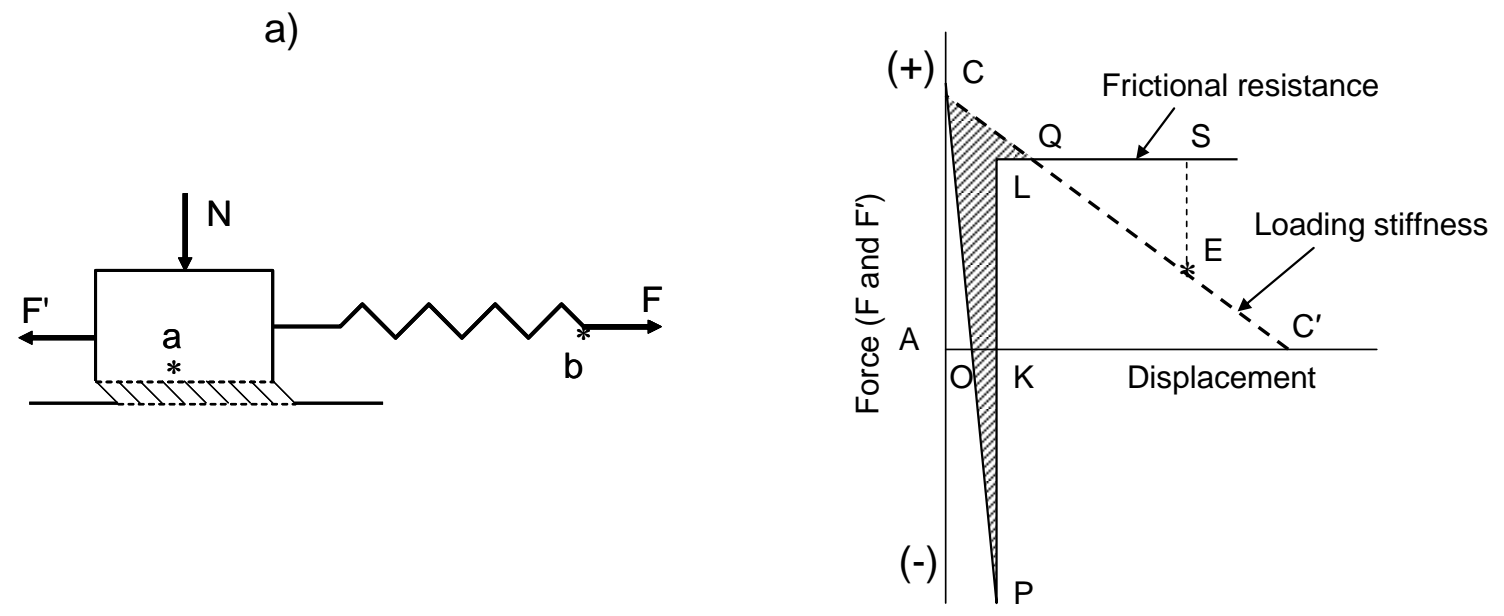

Figure 4 Idealised model of the frictionless structure instability

For simplicity, we ignore the elastic deformation of the fault structure at the increase in force $F$ (point 'a' in Figure 4(a) is stable at loading). In this case, parts of the graph representing loading stages (AC and PL) are vertical. Point $\mathrm{C}$ corresponds to the peak strength at which the block rotation starts. The collaborative diagram in Figure 4(b) shows that the system should lose its stability at point $C$. The instability will occur because there will be a force imbalance $\left(F>F^{\prime}\right)$ that will produce an acceleration of the slider. Beyond point $\mathrm{Q}, F^{\prime}$ becomes greater than the force $F$ in the spring and the slider decelerates, coming to rest at point $\mathrm{E}$, where (in the absence of other dissipation) the area QSE is just equal to CPLQ. The CPLQ area represents the energy released during instability. Important; the resistance to shear here not only disappears completely but becomes negative. It means that the released energy in this case is associated not only with the work done by shear force $F$ (area COKLQ) but also with normal force $N$ (area OPK). All this makes the situation inevitably unstable, acceleration at the beginning stage of instability very rapid and the slip process abnormally violent.

Due to the inertia at dynamic displacement, the equilibrium point at $\mathrm{E}$ lies below the residual frictional strength. The rider will come to rest when all the kinetic energy gained by the rider during the period of acceleration is used up during the period of deceleration. Slip along the fault associated with the stick-slip event begins with a large and rapid drop in shear stress. After the friction restoration the slide continues at a constant residual shear stress level until the end of sliding. 


\subsection{Experimental validation of the frictionless concept}

This paragraph illustrates that traditional methods used for experimental study of rock properties do not allow for the measurement of real fault resistance and displacement associated with the block structure operation. However, the combinations of different kinds of manifestations of the frictionless mechanism observed in experiments presented in this and in the following paragraphs represent quite a convincing basis for the validation of the frictionless idea.

\subsubsection{Problems associated with experimental study of the frictionless mechanism}

Registration of displacement. Figure 5(a) illustrates a traditional method used for registration of loaddisplacement curves for tested specimens. A specimen is equipped with a load cell and two types of gauges for measuring of axial displacement (or strain): an extensometer fixed between two points of the specimen and gauges glued directly to the specimen surface. The failure mode of hard rocks tested at high confining pressure is a localised shear rupture. It should be mentioned again that within the range of high confining pressure where the frictionless mechanism is mobilised (the lowest pressure level is about $50 \mathrm{MPa}$ ) the thickness $h$ of shear rupture is very small. For example, in experiments conducted on dolerite specimens (see results below) the fault thickness was about $0.1 \mathrm{~mm}$. It means that the length $r$ of rotating blocks of the fault structure is of the same order. The displacement along such tiny rotating blocks absorbs a very small amount of energy. The energy consumption of this process at the beginning of displacement is shown schematically in Figure 5(b) by shaded area. A fragment of the post-peak curve characterised by the positive modulus is shown by a solid line.
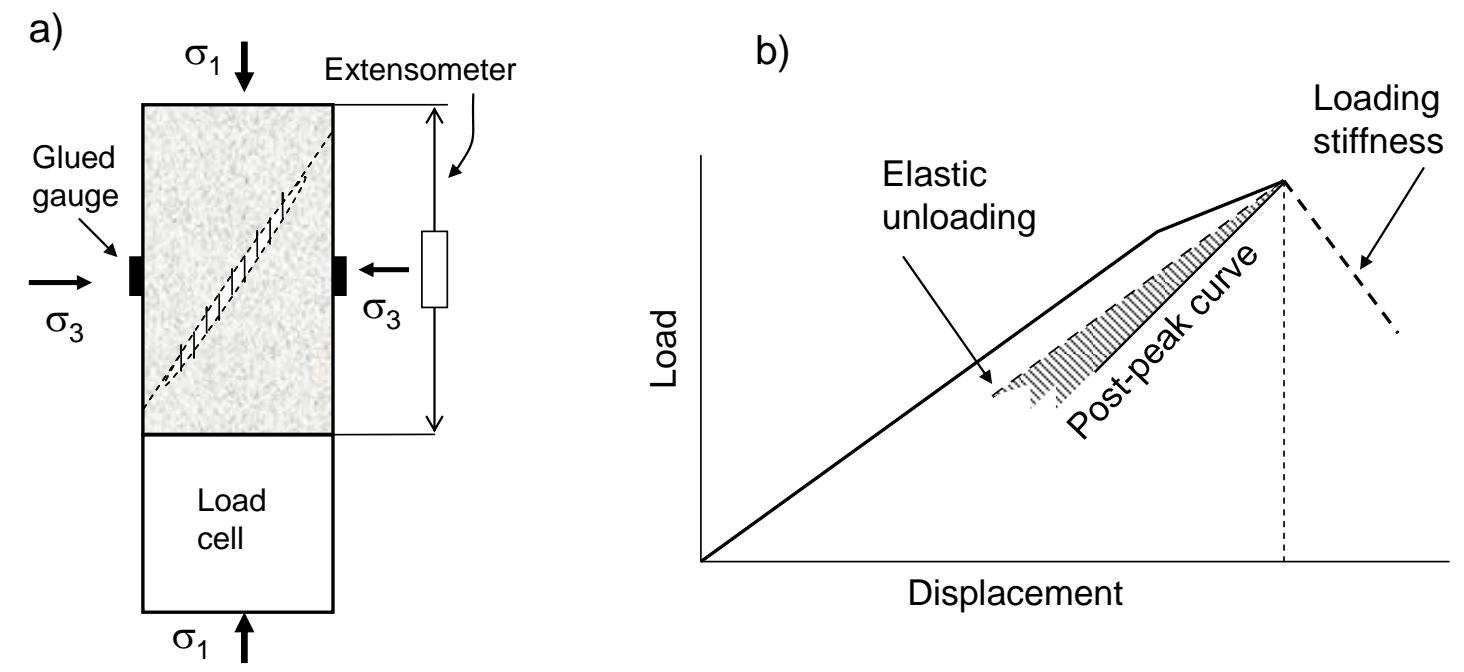

\section{Figure 5 Traditional method used for registration of load-displacement curves}

Due to the frictionless structure forming within the fault zone the rupture process and associated fault displacement is inevitably spontaneous and uncontrollable. The point is that the registration of the post-peak fault displacement by the use of traditional methods is principally impossible in these conditions. It is because the extensometer will reflect the loading stiffness of the loading machine, while the glued gauges will reflect the elastic unloading of the specimen fragments separated by the shear rupture (Figure 5).

Registration of shear resistance. Graphs in Figures 3 and 4 demonstrate that at a certain stage of displacement due to the specific orientation of rotating blocks the fault resistance to shear completely disappears and at the further displacement becomes negative. However, practical registration of the negative resistance is impossible using traditional methods. The reason for that is that the rupture does not occur simultaneously, but propagates from a nucleation region to other regions of the specimen. This makes the local displacement and, consequently, the block orientation and the shear resistance along the fault very irregular. The load cell adjoined to the specimen as shown in Figure 5(a) will register an average resistance of the fault which is normally greater than zero. This is the main reason why the frictionless rupture mechanism has not been detected before. 


\subsubsection{Experimental results validating the frictionless approach}

This paragraph presents two results of experimental studies which support the frictionless concept. Other results will be discussed later. Figure 6 shows a set of stress-strain curves obtained on dolerite specimens tested at different levels of confining pressure. A super stiff and servo-controlled loading machine was used in these experiments. At confining pressures $\left(\sigma_{3} \geq 30 \mathrm{MPa}\right)$ the rupture mode was the same, comprising a single shear plane inclined at an angle $(\alpha)$ of 25 to $30^{\circ}$. The testing showed that the rock brittleness increased with an increase in confining pressure. At $\sigma_{3}=30 \mathrm{MPa}$ it was possible to maintain post-peak stability despite the positive slope of the post-peak branch. At $\sigma_{3}=60$ and $75 \mathrm{MPa}$ the brittleness becomes so high that it was possible only to maintain stability near the start of the post-peak response, after which violent failure occurred. At $\sigma_{3}=100$ and $150 \mathrm{MPa}$ the instability started immediately after the peak strength and was extremely violent.

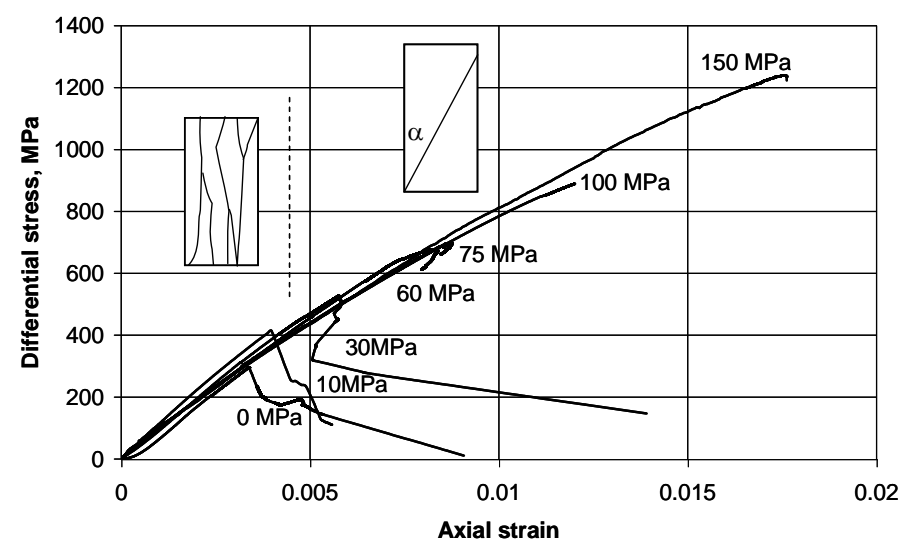

Figure 6 Stress-strain curves and the fracture mode for dolerite specimens tested at different confining pressures (from Tarasov and Randolph, 2007)

Such behaviour is typical for hard rocks. All published results showing the stable (controllable) post-peak failure were obtained at relatively low levels of confining pressure $\sigma_{3} \leq 50 \mathrm{MPa}$ (Lockner et al., 1991). The lack of similar results for higher pressures is explained by the fact that it is impossible to control the rupture process in these conditions. The physical reason for such behaviour of hard rocks is the activation of the frictionless mechanism within a certain range of high confining pressure (operative pressure range of the frictionless mechanism) starting from a critical level. Below this level, the length of rotating blocks is too large to withstand the rotation without failure. This creates friction within the fault zone and corresponding resistance to shear. The rupture process in this case is controllable. Above the critical level, the shorter blocks operate as hinges making the rupture process uncontrollable. The rock embrittlement with increase in confining pressure within the operative pressure range results from a shortening of the rotating blocks. The shorter the blocks, the less displacement is required to provide the same strength degradation and, consequently, the less power consuming the process.

Another experimental result reflects the following feature of the frictionless mechanism. Unresisted dynamic shear during the frictionless stage of displacement may lead to a significant shock wave at the end of this stage due to sharply increased fault resistance resulting from the sudden termination of 'free' rotation of the blocks (see the block mechanism in Figure 3). An example of the variation of differential stress with time during instability for a dolerite specimen failed at confining pressure of $\sigma_{3}=75 \mathrm{MPa}$ is shown in Figure 7 . The stress variation was recorded by a load cell adjoined to the specimen as shown in Figure 5(a). The curve reflects all expected features associated with the frictionless mechanism: i) very low resistance $\Delta \sigma_{\min }$ immediately after the fracture development; ii) an intense shock wave at some stage of the fault displacement; iii) an increase in the specimen resistance after the shock wave. Here $\Delta \sigma_{\mathrm{E}}$ is the resistance at the equilibrium conditions after the instability; $\Delta \sigma_{\text {res }}$ is the residual strength that was obtained after further deformation of the specimen in the static regime. 


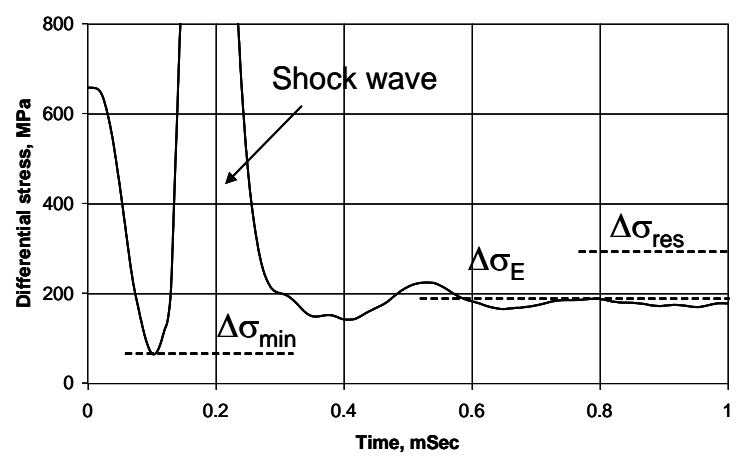

Figure 7 Experimental curve illustrating post-failure shock wave (modified from Tarasov and Randolph, 2007)

It should be noted that the intensity of the shock wave depends on the manner of the shear rupture propagation. It will be shown further that shear ruptures can propagate in two manners: wave-like and jumplike. Such intensive shock waves as shown in Figure 7 can be generated by the jump-like propagating ruptures only. The reason for that is discussed further in the paper.

\subsection{Abnormal rupture violence}

At the frictionless stage of fault displacement, the resistance to shear of the fault and its displacement are inter-related: both of them are determined by the orientation of rotating blocks, see Equations 1 and 2. This fact gives us a chance to restore the post-peak part of load-displacement curves for specimens that show uncontrollable brittle fracture and for which data obtained during the rupture process are inevitably incomplete. This method is described in detail in Tarasov and Randolph, 2007. Figure 8 shows a set of complete load-displacement curves with the post-peak branch restored for dolerite specimens tested at different levels of confining pressure. The acquisition of the complete load-displacement relationship allows estimation of the energy balance of the uncontrollable rupture process. The elastic energy released from the failed specimens is represented on the graphs by shaded areas. This energy is responsible for the rupture violence (the energy released from the loading machine is not considered here). The energy represented by the upper (lighter) part of the shaded area is in accordance with the generally accepted rock behaviour. The bottom (darker) area corresponds to the additional amount of energy released due to the frictionless mechanism operation. This explains the source of energy for abnormal rupture violence observed in the field and in laboratory conditions.

a)

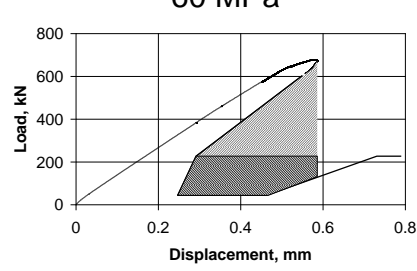

c)

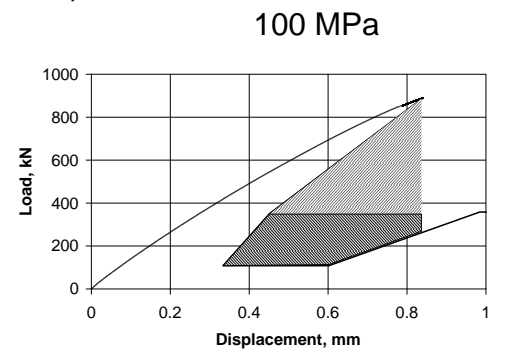

b) $\quad 75 \mathrm{MPa}$

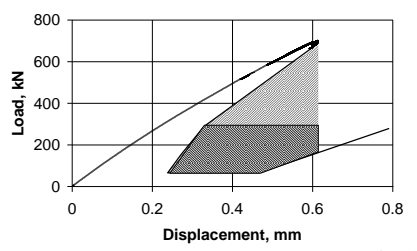

$150 \mathrm{MPa}$

d)

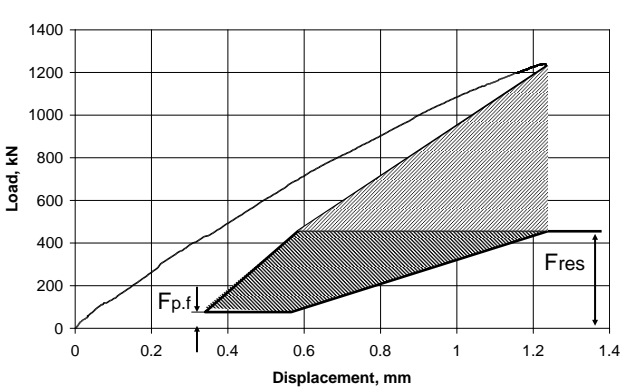

Figure 8 Elastic energy released from dolerite specimens at spontaneous rupture under different confining pressures (modified from Tarasov and Randolph, 2007) 
Figure 8 also demonstrates another very important feature of hard rocks. The increase in confining pressure increases the rock strength and the amount of accumulated elastic energy but does not practically change the post-fracture resistance $F_{p f}$ (prior to mobilisation of the residual frictional strength $F_{r e s}$ ). This imbalance in the rock properties is the source of abnormal increase in the rupture violence with increase in confining pressure (or depth).

\subsection{Critical stresses and operative range for the frictionless mechanism}

The frictionless mechanism is activated within a certain range of confining pressure (or minor stress) where the rotating blocks can operate as hinges. We call this pressure range the operative pressure (stress) range. Figure 9 illustrates the variation in load-displacement rock properties with increase in confining pressure and corresponding operative pressure range. The physical meaning of the lower critical stress below which the frictionless mechanism is not applicable, has been previously discussed. At the upper critical stress the fault structure behaviour returns to normal frictional conditions under the effect of increased material ductility and exceedingly high stresses applied to the rotating blocks (which become very short at this level of pressure). We can expect the efficiency of the frictionless mechanism operation in respect of the rock embrittlement and elastic energy release to have a maximum, as shown in Figure 9.

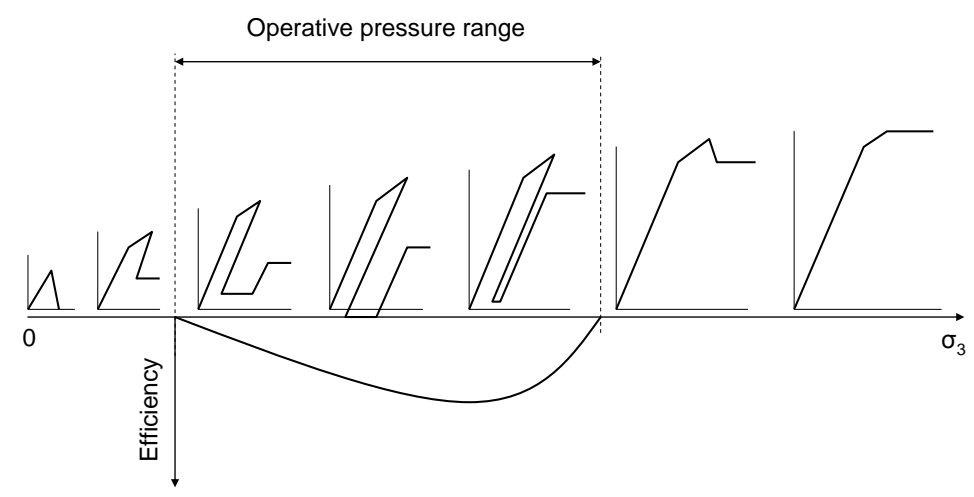

Figure 9 Variation in load-displacement rock properties with increase in confining pressure

Modern earthquake seismology considers the development of faults in the earth's crust as a process taking place in a significantly fractured crustal structure where the strength and behaviour of rock is determined by a friction law (Nur, 1978; Tse and Rice, 1986; Scholz, 2002). Earthquakes (as well as shear rupture rockbursts) are the attribute of great depth. They normally take place below some critical depth and increase their violence and activity with depth. The frictionless approach proposes new mechanisms which can explain the existence of upper and bottom cut-off in seismicity and the location of maximum seismic activity at an intermediate depth.

Another very important feature of shear rupture rockbursts is the nucleation within the rock space at a point some distance away from the surface of an opening, unlike other types of rockbursts (for example, strainburst, buckling, face crush) which occur right at the surface (Ortlepp, 2000). Abnormal properties of hard rocks induced by high confining pressure (as discussed previously) explain such features. Hard rocks exhibit these properties of extreme brittleness and very low post-failure strength $\left(\tau_{\mathrm{p}-\mathrm{f}}\right)$ at confining pressure above some critical level.

The opening presented in Figure 10 is located below the critical depth where the abnormal rock properties are activated. The graph shown at the top of the figure characterises the distribution of the minor stress $\left(\sigma_{3}\right)$ around the opening. A range of minor stresses located above the critical stress represents an operative range of stress where the frictionless mechanism is applicable. The graph at the bottom of the figure symbolises the distribution of the differential stress $\left(\Delta \sigma_{1}\right)$ around the opening. A maximum of the $\Delta \sigma_{1}$ stress concentration is located some distance from the open surface. 


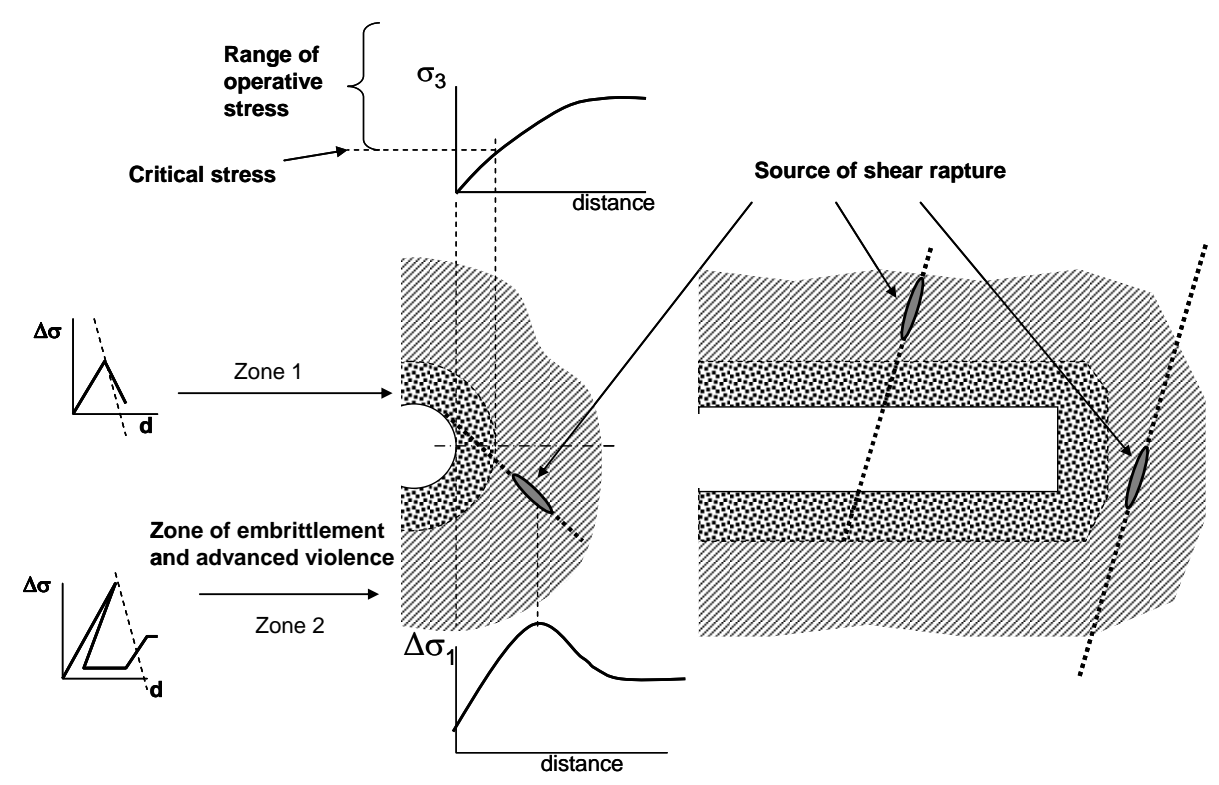

Figure 10 Zone of embrittlement and advanced violence around an opening (from Tarasov and Randolph, 2007)

In the rock mass surrounding the opening, two zones of different rock behaviour can be distinguished. Zone 1 is characterised by a level of minor stress below the operative range. Rocks in these zones exhibit normal behaviour. A possible relation between the post-peak rock stiffness and loading stiffness for this zone is illustrated by a graph to the left of the figure, which characterises the situation in this zone as stable. The situation in zone 2, by contrast, is abnormal and unstable despite the fact that the loading stiffness here is the same. Rocks in this zone have extreme brittleness due to the frictionless mechanism. A new fracture can be initiated at any point within this zone where the level of shear stress, caused by the stress concentration, exceeds the rock strength. The rupture development will be violent. The direction, attitude and extent of this rupture are determined by the prevailing stress field. By analogy, tectonic stresses taking place in the earth's crust can also initiate new shear ruptures in pristine rocks at great depth in the form of earthquakes.

\section{Shear fracture nucleation and propagation in hard rocks}

\subsection{Common knowledge}

Shear fractures (faults) are very complicated mechanical formations with a specific structure. Properties and behaviour of faults are determined by internal mechanisms governing the structure development and external mechanisms of the fault interaction with the surrounding medium. These two types of mechanisms are interrelated and should be taken into account for a full understanding of the shear rupture phenomenon. Models reflecting the external mechanisms normally consider faults as a structureless formation or as a mathematical line along which mode-II cracks may propagate dynamically. These type of models have been developed extensively, resulting in significant progress in the understanding of shear rupture (Das, 1985; Domowska and Rice, 1986; Broberg, 1999; Rice, 2001; Scholz, 2002; Freund, 1990; Rosakis, 2002). However, neglecting the internal mechanisms in these models can sometimes lead to incorrect conclusions. For instance, the natural tendency of faults to exhibit segmentation, wavy fault paths and intense micro-cracking should significantly decrease the maximum achievable rupture speed in real faults compared with theoretical predictions made for idealised models.

An important breakthrough in understanding the internal mechanisms responsible for the development of fault structure was made recently when the role of the block structure in the rupture nucleation and propagation was recognised (Moore et al., 1990; Lockner et al.,1991; Reches and Lockner, 1994). In hard rocks, a fault nucleates by local interaction between a few micro-cracks and propagates into the unfaulted regions by inducing new micro-crack growth at its tip; this eventually forms a specific fault structure - an echelon of blocks (slabs, beams) separated by tensile cracks (see Figure 2). The fault displacement along 
such a structure is accompanied by rotation, buckling and failure of the blocks. Three characteristic zones in the propagating shear fracture were distinguished: i) a process zone that lies at the head of the fracture, where an echelon of micro-cracks develops, oriented parallel to the maximum compressive stress direction; ii) a core zone consisting of comminuted rock material, which forms immediately after the fault front has passed through; iii) a damage zone, which comprises a broader volume of more distributed irreversible deformation around the fault.

However, many questions associated with the fault structure development are still unclear. In particular, questions concerning such features as: fault segmentation and linkage between segments; curvilinear traces of shear fractures; length of the process zone; critical fracture length required for instability; intersonic speed of fracture propagation. This paper presents a new approach to resolve these questions based on the frictionless concept. In our discussion we will use the following simple classification of faults:

i) Primary shear fractures - continuous thin ruptures with uniform structure.

ii) General faults - complex discontinuous systems comprising primary fractures, segments, overlap regions, junctions, and other geometric complexities.

We will discuss first features of the development of primary fractures and then features of general faults. It will be shown that despite the similarity in the fault structure (rotating blocks), the mechanisms governing the development of these two forms of shear ruptures, as well as certain properties of them, are markedly different. This subject has been discussed earlier by Tarasov $(2007,2008)$.

\subsection{Primary shear fracture}

\subsubsection{Structure and propagation}

Primary fractures are normally thin and continuous formations with thickness ranging from fractions of a millimetre to a few millimetres. Figure 11 illustrates new principles of the primary fracture development. Figure 11(a) represents a potential fault before the onset of its development. The eventual fault structure, comprising an echelon of blocks, does not exist initially, but will be created (activated) sequentially during the fault development. The eventual (potential) structure is shown here to illustrate that the rotation of activated blocks within the fault zone causes a transient increase in the fault thickness (in the vertical direction) but does not affect the material body along the fault (in the horizontal direction). Orientations of major $\sigma_{l}$, minor $\sigma_{3}$, shear $\tau$ and normal $\sigma_{n}$ stresses applied to the material body are shown in Figure 11.

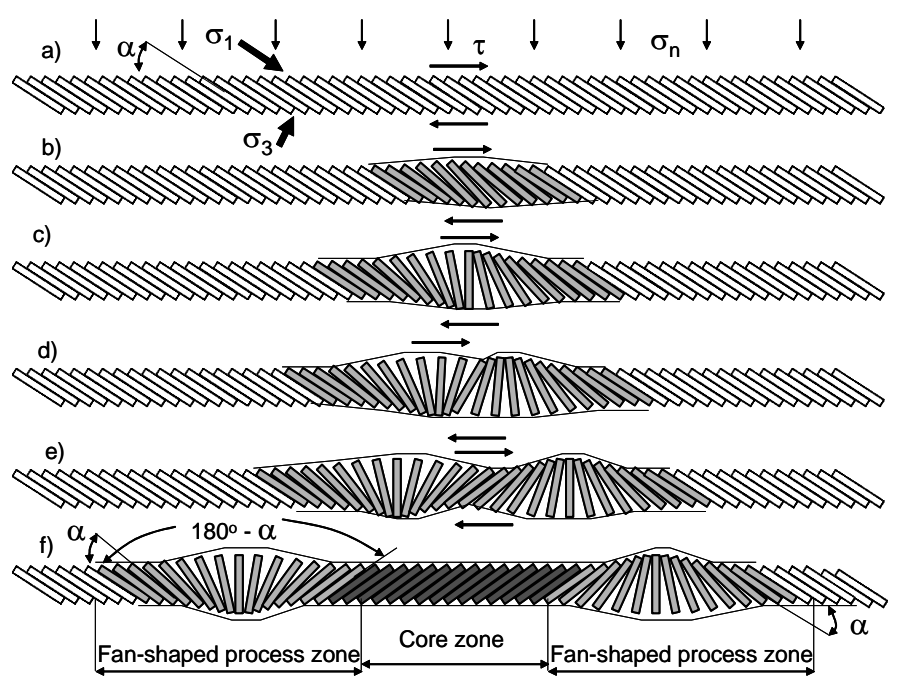

Figure 11 Idealised model of shear fracture propagation governed by the fan-shaped mechanism (from Tarasov, 2007) 
Five stages of the fault development are shown here. When shear stress approaches the level of ultimate shear strength the process of formation of the fault structure will start within the most suitable area of the material body determined by the local material strength and stress conditions. This process involves creation of tensile cracks and blocks between them and rotation of the blocks in response to the fault displacement. In accordance with the frictionless concept blocks representing the fault structure can rotate from the initial angle $\beta=\alpha$ up to the final angle $\beta=180^{\circ}-\alpha$, where $\alpha$ is the angle of initial orientation of the tensile cracks (and blocks) in respect to the fault axis. At the rotation, a series of blocks eventually forms a fan-shaped structure at the head part of the propagating fracture (Figure 11). The fan-shaped structure should be formed inevitably because this is the only possible mechanism which can provide the block rotation at shear displacement within initially solid medium. The fan-shaped structure represents the process zone which is strictly determined in this model compared with existing models. The core zone in this case is represented by blocks that have completed their rotation. Within the core zone the friction is completely restored and the fault strength here is characterised by normal frictional resistance.

\subsubsection{Fan-shaped self-equilibrating mechanism}

The fan-shaped mechanism is the key feature of dynamic rupture propagation. The mechanism of rotating blocks makes the fault resistance along the head of propagating rupture very specific. Figure 12 shows a front part of propagating (from left to right) fault involving the fan-shaped head. Directions of applied shear $\tau$ and normal $\sigma_{n}$ stresses are indicated on the schema. A graph under the fault illustrates schematically the shear stress distribution ahead of the fault (dotted curve plotted in accordance with experimental results and existing models) and the shear resistance of the fault itself as a function of the fault structure condition (solid curve). The stress level far ahead of the fault is approximately equal to the initial stress at which the fault started propagating from the weakest (nuclear) zone. In the immediate vicinity of the rupture head due to stress concentration the stress level increases up to cohesive strength (or slip-failure strength) at which a special rupture process is activated.

a)

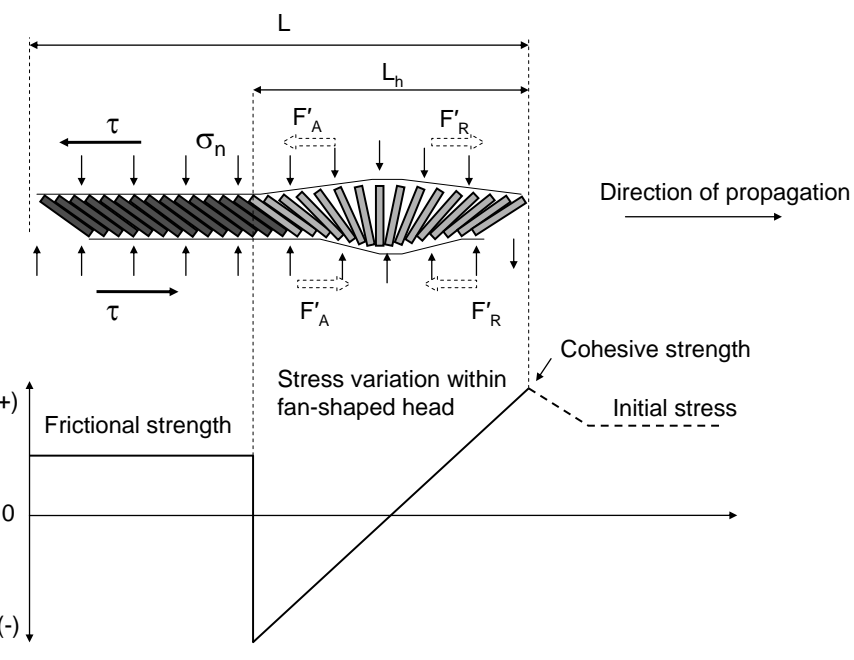

b)

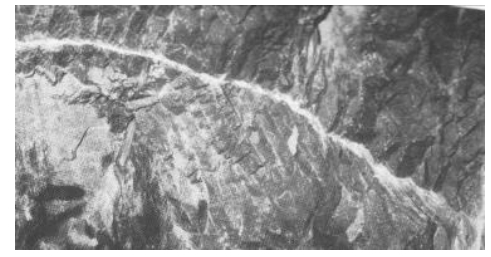

Figure 12 a) Fan-shaped structure as a self-equilibrating mechanism; b) Illustration of the curvilinear propagation of primary fractures provided by the fan-shaped mechanism (photograph from Ortlepp, 1997)

The special rupture process associates with formation of tensile cracks and blocks between them which rotate due to shear displacement of the fault faces. The rotating blocks under the effect of normal forces applied to the fault make the resistance to shear within the fault variable in accordance with the block orientation (relation between fault resistance and angle $\beta$ is shown in Figure 3). Within the front half of the head the resistance to shear is positive and reactive forces $F_{R}^{\prime}$ counteract to shear. Within the back half of the head active forces $F_{A}^{\prime}$ assist to shear making the shear resistance here negative. The maximum resistance takes place at the front edge of the head; the minimum (negative) resistance is at the back edge of the head. The 
integral values of reactive $F_{R}^{\prime}$ and active $F_{A}^{\prime}$ forces within the fan-shaped structure are equal to each other (in the idealised model). It means that the total shear resistance of the head is equal to zero: $F_{R}^{\prime}+F_{A}^{\prime}=0$. Thus the fan-shaped structure represents a self-equilibrating mechanism of the rupture propagation. The head moves as a wave, propagating the fracture. At the end of the head the blocks have completed their rotation. Behind the head, the fault structure is very compact forming the core zone with normal frictional resistance to shear.

It is important to note that despite the negative shear resistance of the second half of the fan-shaped head the average shear resistance of the whole fault (involving the process and core zones) is always positive. This explains the reason why the minimum stress level on the experimental curve in Figures 7 and 8 are positive. A further important feature of the fan-shaped structure is the creation of compressive and tensile stresses within the opposite surfaces of the fracture (see Figure 12), which can initiate tensile cracks within the extended surface of the fracture. The existence of a damaged zone along the extension fracture surface is well-documented and may be explained by alternative mechanisms (Segall and Pollard, 1980; Moore and Lockner, 1995; Vermilye and Scholz, 1999; Rosakis, 2002). The fan-shaped structure represents an additional mechanism causing this known effect.

The fan-shaped head can propagate independently on the core zone (the core zone can be stable). In this case the fault displacement is restricted by the displacement associated with the block rotation $d_{r}=2 r \cos \alpha$ (see Figure 13(b)). Here $r$ is the block length; $\alpha$ is the angle of the initial block orientation. Due to independent moving of the fan-shaped head and resulting very small displacement of the shear fracture, it can create very curvilinear traces similar to that shown in Figure 12(b). The waviness of the fracture in this case is determined by non-uniformity in material strength and local stress conditions.

\subsubsection{Stress variation at the rupture propagation}

Let us analyse the breakdown process in the context of the fan-shaped rupture mechanism. Figure 13(a) shows four stages of the shear rupture propagation. The rupture propagates from left to right. For simplicity we assume that the upper fault surface moves to the left while the bottom surface stays stable. In accordance with the fan-shaped mechanism the fault displacement is accompanied by the block rotation. Each block rotates from the initial position $(\beta=\alpha)$ representing the front block to the final position $\left(\beta=180^{\circ}-\alpha\right)$ representing the back block of the fan-shaped head (see Figures 13(a) and 13(b)).

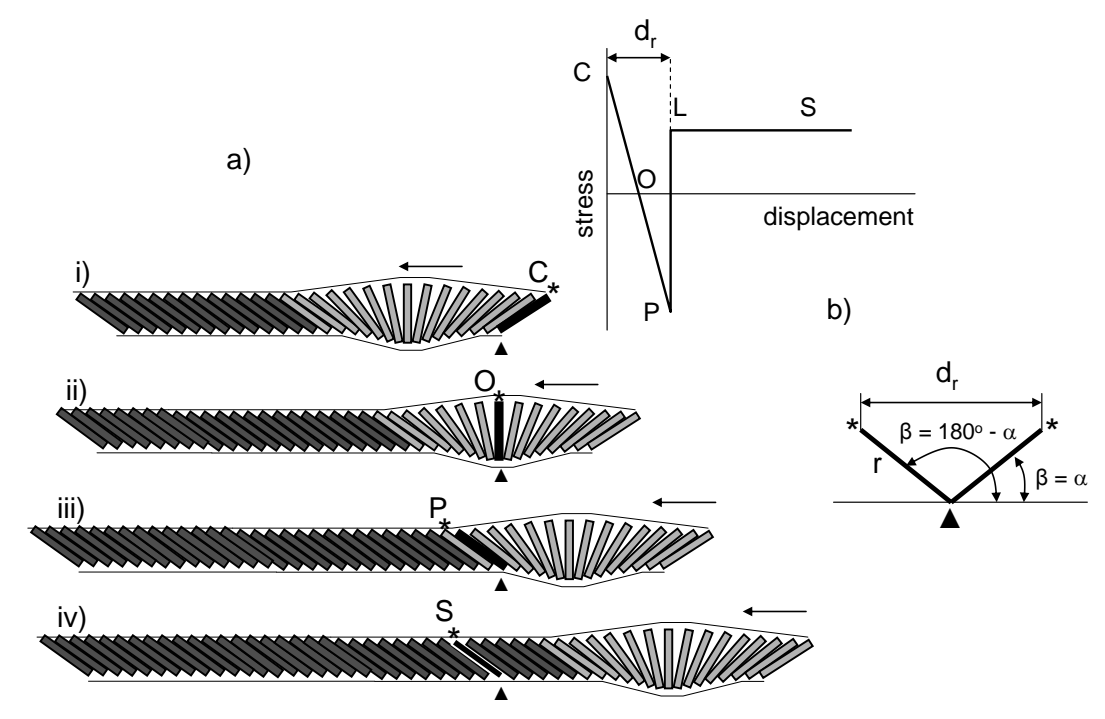

Figure 13 Stress variation in two points (marked by an asterisk and a triangular) of the rupture surfaces associated with rotation of the same block (show in black) at the rupture head propagation 
The block orientation within the structure determines the local structure resistance to shear and, correspondingly, the local shear stress on the fault surfaces. The stress-displacement curve in Figure 13(a) illustrates the shear stress variation in two points of the rupture surfaces (marked by a triangle and an asterisk) associated with rotation of the same block (shown in black) at the rupture head propagation. At the beginning stage-i the black block represents the front block of the head with maximum resistance to shear corresponding to point $\mathrm{C}$ on the stress-displacement curve. At other three stages the black block orientation corresponds to shear resistance equal to: zero (point $\mathrm{O}$ ); minimum value (point $\mathrm{P}$ ); and residual frictional level (LS). The displacement $d_{r}$ associated with rotation of the same block from its initial to final position is $d_{r}=2 r \cos \alpha$ (see Figure 13(b)). Here $\mathrm{r}$ is the block length; $\alpha$ is the angle of the initial block orientation.

It is important to accentuate that the shear stress variation shown in the both graphs in Figures 12 and 13 represents the shear resistance of the fault structure. Exactly the same stress variation takes place on the fault surfaces only which are in direct contact with the structure. At a point located at some distance from the fault surfaces the material is subjected to an average stress. The contribution of local stresses generated on the surfaces of fan-shaped head to the average stress decreases with distance from the surfaces. At a distance exceeding some critical value the average stress should be practically insensitive to the local stress variation within the rupture head.

\subsubsection{Experimental verification of the frictionless nature of the rupture propagation}

To prove experimentally the proposed in Figure 13 character of the stress variation induced by a propagating shear rupture it is necessary to fix gauges in the immediate vicinity of the rupture surfaces. Figure 14(a) illustrates symbolically the difference between local stress-displacement relations (solid curves) taking place in points located at different distance from the fault surfaces. On the rupture surface (point 1) the stressdisplacement variation associates totally with the block structure behaviour. At some critical distance from the fault (point 3) the stress-displacement variation associates totally with the loading system behaviour. Between these two points the stress-displacement behaviour of the material is represented by intermediate values.

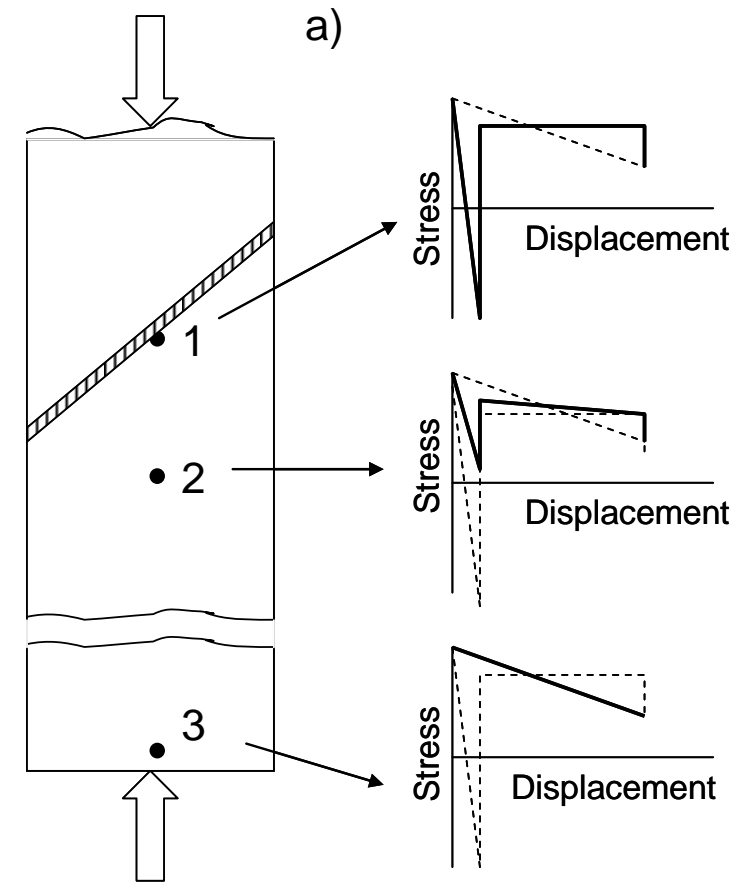

b)

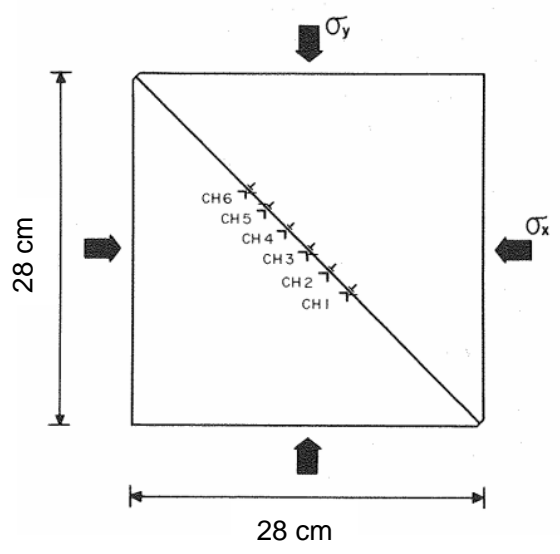

Figure 14 a) Variation of stress-displacement response at the rupture propagation recorded by gauges fixed at different distances from the rupture surface; b) General view of a specimen used in stick-slip experiments (from Ohnaka and Kuwahara, 1990) 
Unfortunately, it is impossible to guess the rupture position at testing of pristine rock specimens for proper installation of gauges. The most realistic method which allows studying the stress variation associated with shear rupture propagation is the use of hard rock specimens with precut faults. The proposition that the frictionless mechanism can be also the source mechanism of the brittle stick-slip instability (Tarasov, 2008) is based on the following interpretation of friction. The modern concept of friction is attributed to Bowden and Tabor (1964). They envisioned all real surfaces as having topography. When such surfaces are brought together they only touch at contact areas. They then supposed that, due to the very high compressive stress at the contact points, adhesion occurred there, welding the surfaces together at "junctions". So, the junctions here represent zones of welded (restored) material. At shear displacement along the surfaces, these junctions would have to be sheared through. It is because any shear rupture in hard rocks propagates due to the formation of tensile cracks and rotating blocks we can expect the manifestation of features of the frictionless mechanism at stick-slip instability.

Let us analyse results obtained by Ohnaka and Kuwahara (1990) on granite specimens at study of stick-slip instability. Stick-slip was generated along a $40 \mathrm{~cm}$ long precut fault oriented at $45^{\circ}$ to the specimen axis (Figure 14(b)). The sliding surfaces were ground flat. The maximum height roughness was of the order of $5 \mu \mathrm{m}$ for traverses about $2 \mathrm{~cm}$ long. A series of semiconductor strain gauges (active gauge length $2 \mathrm{~mm}$ ) were mounted at $2.5 \mathrm{~cm}$ interval at positions $5 \mathrm{~mm}$ from the fault for monitor local shear stresses and displacements.

a)

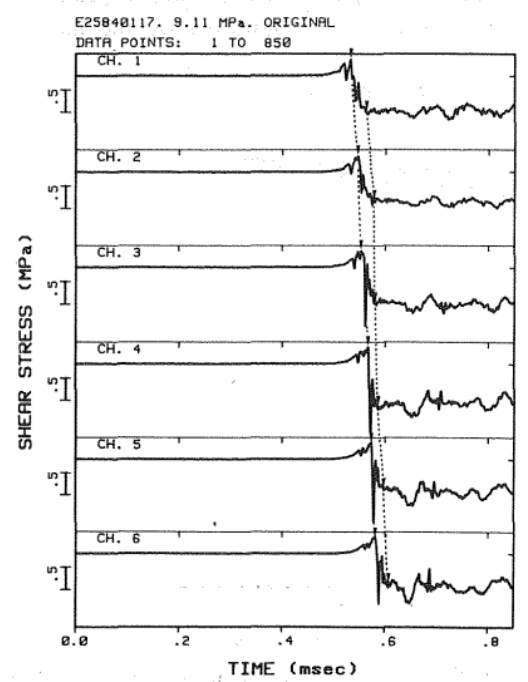

b)
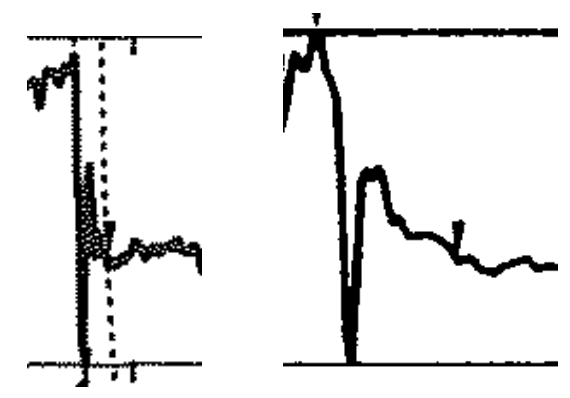

Figure 15 Stress-time variation recorded by different gauges fixed along the propagating rupture on the specimen shown in Figure 14(b) (from Ohnaka and Kuwahara, 1990)

Figure 15 indicates a series of recorded signals for local shear stresses along the fault at the rupture propagation. The graph's shear stress versus time, show that the rupture propagates from gauge CH.1 to gauge CH.6. In the region between gauges $\mathrm{CH} .3$ and $\mathrm{CH} .6$ the rupture propagates steadily at the speed of about $3 \mathrm{~km} / \mathrm{s}$. The obtained results indicate that the character of the local stress variation here (see magnified curves in Figure 15(b)) is similar to that discussed for the frictionless mechanism: i) intensive stress drop below the frictional level; ii) shock wave; iii) restored frictional resistance.

Unfortunately, the negative stress level was not also recorded here. The reason for that is the relatively large distance between the rupture surfaces and gauges. The maximum height roughness of the specimen surfaces here is about $5 \mu \mathrm{m}$. We can suppose that the fault thickness (or length of rotating blocks) formed in junctions representing contact areas between these asperities should be of the same order. In the case of such tiny fault structure the distance of $5 \mathrm{~mm}$ from the fault to the mounted gauges is relatively large to measure correctly the local stress variation taking place on the rupture surfaces. The stress variation obtained in the experiments is similar to that in Figure 14(a) at point 2. 
It should be explained also why the shock wave associated with the sharp friction restoration following the stage of the frictionless displacement is not such significant in these experiments compared with results presented in Figure 7. The intensive shock wave takes place when a large group of blocks of the fault structure rotates simultaneously (see Figure 3). Such block behaviour takes place in the case of jump-like character of the fault propagation based on the advanced fault triggering (discussed further in the paper). In the case of wave-like manner of the rupture propagation (fan-shaped mechanism) the blocks rotate sequentially which mitigates dramatically the shock-wave effect.

a)
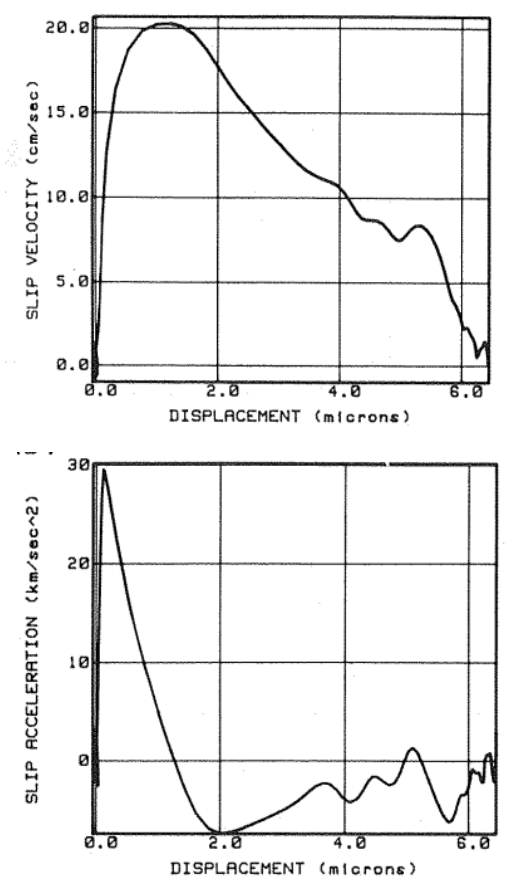

b)

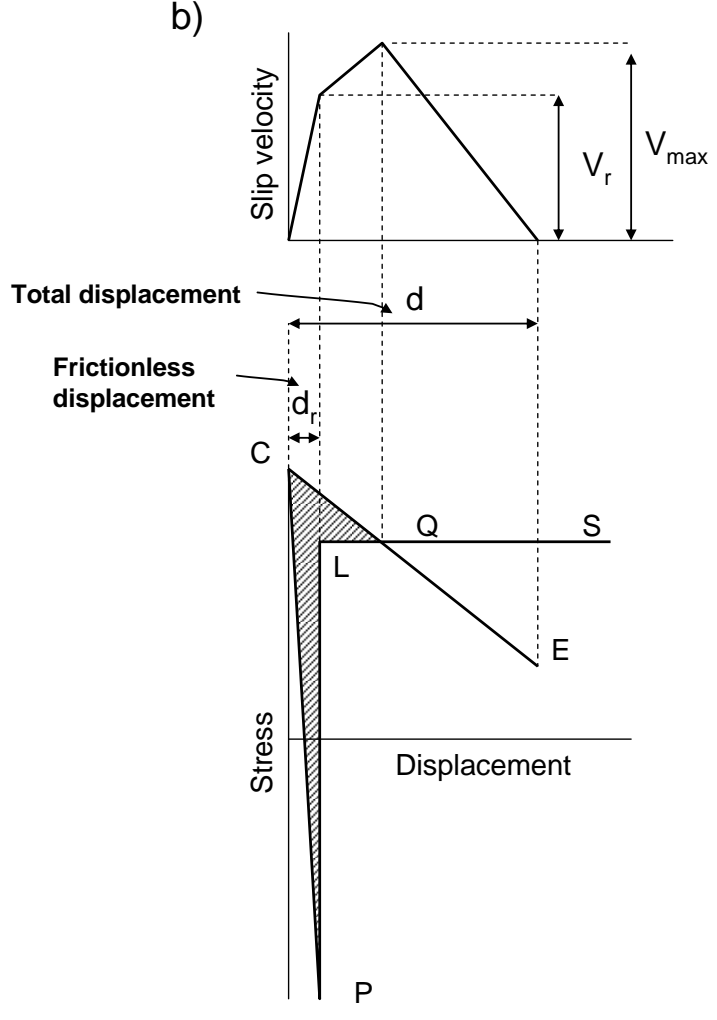

Figure 16 a) Local variation of slip velocity and slip acceleration at the rupture propagation (from Ohnaka and Kuwahara, 1990); b) Explanation of the rapid slip velocity acceleration at the beginning of the slip process (from Tarasov, 2008)

The following result represents yet more important evidence of the fact that the frictionless mechanism is the source of the brittle stick-slip instability in the discussed experiments. Let us analyse the character of local displacement of the fault surfaces at the rupture propagation. Graphs in Figure 16(a) illustrate the variation of slip velocity and slip acceleration of a local zone of the rupture surface at the rupture propagation. The main feature of these results is the fact that the velocity accelerates very rapidly at the beginning stage of displacement. The maximum slip acceleration is attained at displacement of about $0.3 \mu \mathrm{m}$ and the maximum slip velocity $V_{\max }=20 \mathrm{~cm} / \mathrm{sec}$ corresponds to displacement of about $1.2 \mu \mathrm{m}$. The total displacement is about $6 \mu \mathrm{m}$. For such behaviour a powerful source of energy is required at the beginning stage of displacement. The traditional understanding of the rupture process with the frictional rupture behaviour cannot propose the plausible explanation of this fact, but the frictionless concept can do this.

Figure 16(b) illustrates the following explanation. The curve CPLS of the bottom graph here represents the stress variation in a point of the fault surface at its displacement associated with the rupture propagation. Such stress variation explained in Figure 13 is caused by the frictionless mechanism. Line CE represents stiffness of the stressed surrounding medium. The instability starts at point $C$. Point $E$ is the point of regained stability. The shaded area corresponds to the energy released from the surrounding material at the local unstable fault displacement. The total energy released is responsible for the maximum value of slip velocity $V_{\max }$. The graph shows that the major amount of energy is released at the beginning frictionless stage of the 
displacement $-d_{r}$. This energy is the source of the sharp acceleration of the slip velocity observed in the experiments. A theoretical curve of slip velocity versus displacement is shown on the top of Figure 16(b).

\subsubsection{Critical fracture length}

The nature of rock fracture development is that unstable propagation is foregone by a preceding phase of deformation. The correct understanding of the physical processes taking place at this phase is extremely important for predictive purposes. Knowing the physical mechanism it is possible, in particular, to determine with a higher degree of certainty the critical fracture length $L_{c r}$, which indicates the boundary between stable and unstable phases of the fracture process. Existing crack and friction-slider models do not consider the detailed physical mechanisms operating in the fracture zone and define the critical length independently of the fault structure (Andrews, 1976; Ida, 1982; Scholz, 2002). For example, in crack models $L_{c r}$ is determined from the assumption that a characteristic fracture energy per unit area is required for the crack to propagate. In the stick-slip models, rupture is assumed to occur when the stress on the fault reaches the static friction value and the condition for dynamic instability exists.

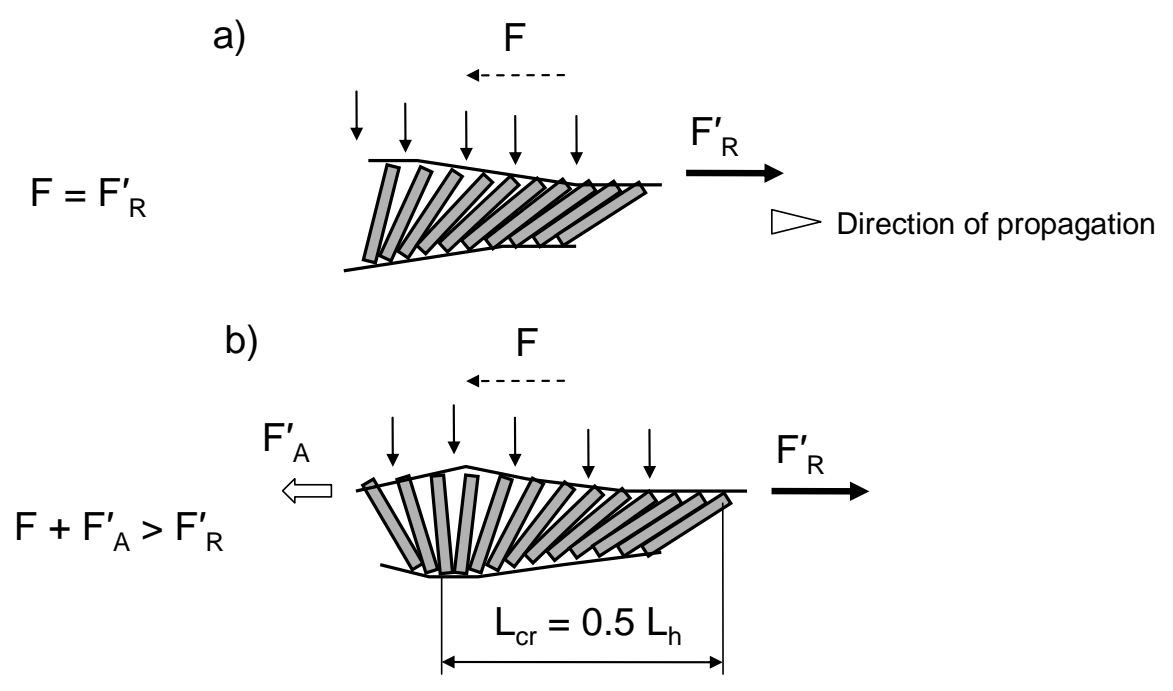

Figure 17 Critical fracture length

The fan-shaped concept provides another approach to understanding of this phenomenon. According to the model the instability starts when the fan-shaped mechanism creates an additional active force $F_{A}^{\prime}$ which disturbs the balance between the applied $F$ and reactive $F^{\prime}$ forces (see Figure 17). For idealised conditions the minimum critical length $L_{c r}$ should correspond to the half length of the fan-shaped head $L_{h}$. The length $L_{h}$ in this approach is a function of the geometrical characteristics of the fault structure (length of rotating blocks $r$, angle of the initial block orientation $\alpha$, initial distance between the block axis $s$ (see Figure 3), elastic modulus of the face material $E$, and normal stress $\sigma_{n}$ :

$$
\mathrm{L}_{\mathrm{cr}}=0.5 \mathrm{~L}_{\mathrm{h}}=\mathrm{f}\left(\mathrm{r}, \alpha, \mathrm{s}, \mathrm{E}, \sigma_{\mathrm{n}}\right)
$$

$L_{c r}$ increases as $E, r$, and $s$ increase, and decreases as $\sigma_{n}$ and $\alpha$ increase.

\subsubsection{Rupture velocity mechanism}

Experimental results which are common to these studies are: i) rupture velocities are of the order of the seismic wave speeds; ii) particle or slip velocities are orders of magnitude less; iii) slip velocities are related to the stress drops (or energy released) accompanying the stick-slip failures (Wu et al., 1972; Johnson et al., 1973; Ohnaka, 1973; Ohnaka et al., 1986; Ohnaka and Kuwahara, 1990). The physical mechanism which determines the relation between the slip (particle) and rupture velocities is still unclear. Using the new approach proposed in this paper it is possible to clarify the physical reason of this relation. 
Figure 18 shows a shear rupture comprising the fan-shaped head and the core zone at three stages of the rupture propagation. The fan-shaped head is shown symbolically with two extreme blocks located at the front and at the back of the head. It should be remembered that each block involved in the fan-shaped structure is subjected to rotation from the initial position $(\beta=\alpha)$ representing the front block to the final position $\left(\beta=180^{\circ}-\alpha\right)$ representing the back block (see Figure 13). The fault displacement associated with the total rotation of the block is equal to $d_{r}$. The block rotation takes place in the initially solid medium and each block rotates in strong interconnection with an echelon of similar blocks of the fan-shaped structure. In such condition to provide the full rotation of each individual block from the initial to the final positions the relatively long fan-shaped structure (head) is required. As stated earlier, the head length $L_{h}$ is a function of geometrical characteristics of the fault structure, elastic modulus of the face material $E$, and normal stress $\sigma_{n}: L_{h}=f\left(r, \alpha, s, E, \sigma_{n}\right)$.

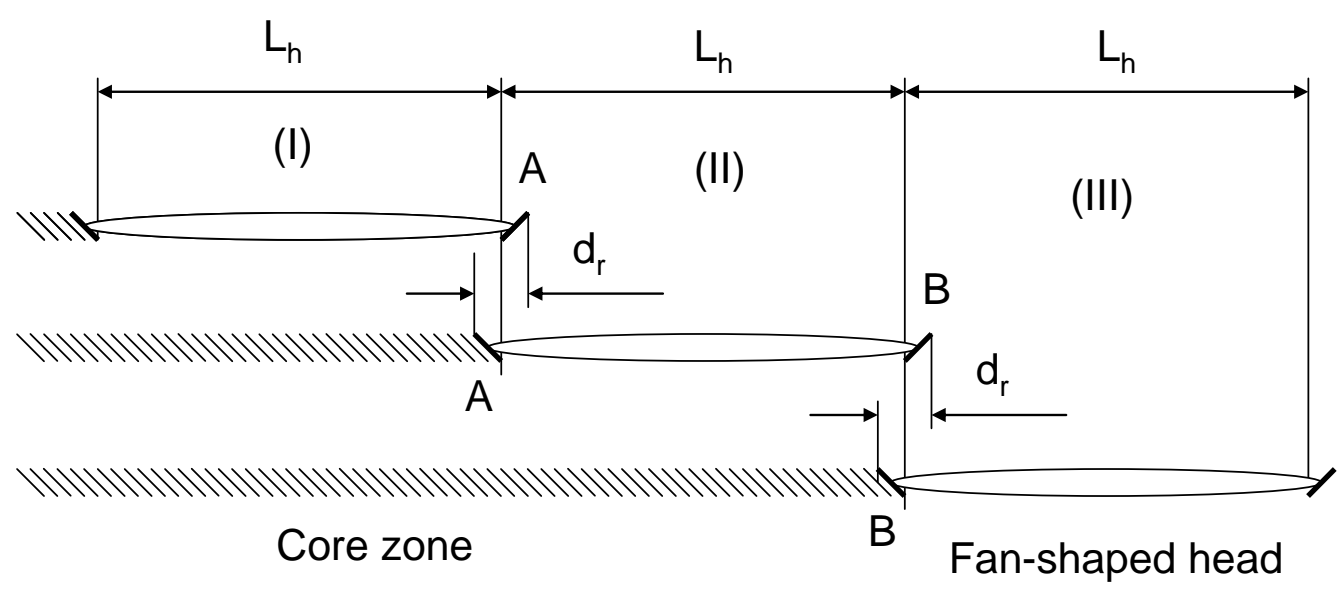

Figure 18 Relation between fault displacement $d_{r}$ and fault propagation $L_{h}$ determined by the fanshaped mechanism (from Tarasov, 2008)

Figure 18 illustrates situations at which the same block representing the front block of the head at a previous stage (e.g. block A at stage I or block B at stage II) becomes after completion of its rotation the last block of the head at the following stage (e.g. block A at stage II or block B at stage III). Figure 18 shows that at the displacement equal to $d_{r}$ the rupture propagation is equal to $L_{h}$. The fault displacement associated with the block rotation and the corresponding rupture propagation occurs synchronically. It means that the ratio between velocities of these two processes is also determined by the ratio $d_{r} / L_{h}$.

It is important, that each individual block rotates with acceleration: the initial speed is zero; the final speed at the back edge of the moving fan-shaped head corresponds to slip velocity $V_{r}$ (see Figure 16(b)). This velocity $V_{r}$ is maintained constant at the back edge of the moving fan-shaped head by an echelon of blocks sequentially participating in the rotation process. In this situation the dislocation of the front edge (tip) of the fan-shaped head occurs with a speed equal to the rupture velocity $V_{\text {tip }}$. Hence, the ratio between slip $V_{r}$ and rupture $V_{t i p}$ velocities is determined by the ratio between parameters $d_{r}$ and $L_{h}$ :

$$
\frac{V_{r}}{V_{t i p}}=\frac{d_{r}}{L_{h}}
$$

Thus, the fan-shaped structure is a transmission mechanism which transforms relatively slow shear displacement of the rupture surfaces into very fast dislocation of the rupture tip. The slip velocity is determined by the energy released from the material surrounding the propagating rupture head. We should emphasise that in accordance with the discussed mechanism the only part of released energy associated with displacement $d_{r}$ affects the rupture velocity (see Figure 16(b)). The energy released during the following frictional sliding along the core zone (LQ on the graph) does not affect the rupture velocity. 
Using experimental data presented in Figure 16(a) we can estimate values of all parameters involved in Equation 4 . We have that $d_{r} \approx 0.3 \mu \mathrm{m}$ and $V_{r} \approx 13 \mathrm{~cm} / \mathrm{sec}$. The rupture tip velocity measured in this test was $V_{t i p}=3 \mathrm{~km} / \mathrm{sec}$. Using Equation 4, we can calculate the length of fan-shaped head: $L_{h}=7 \mathrm{~mm}$.

\subsubsection{Maximum attainable rupture velocity}

The maximum attainable rupture speed is a very important characteristic of the rupture process. To better understand the situation regarding shear fracture propagation, let us consider a similar question for mode-I cracks. The theoretical limit for the mode-I crack speed $v$ in a homogeneous solid is the Rayleigh speed $c_{R}$ which is approximately $90 \%$ of the shear wave speed $c_{S}$ in the same material (Freund, 1990; Broberg, 1999). This limit is obtained by assuming that an opening crack will propagate along a perfectly straight crack path in the homogeneous material. In special experiments where such conditions were artificially provided the predicted limiting speed was approached, in particular, in tests conducted on fabricated weak planes in a homogeneous material by bonding two identical plates of a brittle polymer (Washabaugh and Knauss, 1994). In real materials, however, the speed has never been observed to exceed $0.65 c_{R}$. Furthermore, in the overwhelming majority of cases the speed was only about 30 to $40 \%$ of $c_{R}$. The reason for that is the natural tendency for physical cracks to follow a wavy path and for micro-branching, which results in a significant increase in micro-crack population and, consequently, in the fracture energy (Ravi-Chandar and Knauss, 1984; Johnson, 1992; Gao, 1993).

For mode-II (shear) cracks the theory predicts the ability to propagate intersonically, that is at speeds between the compression wave speed $c_{P}$ and the shear wave speed $c_{S}$ (Freund, 1990; Brogerg, 1999). The theoretical models consider a crack propagating along a predetermined weak and straight-line crack path between two isotropic linear elastic solids. Experiments with brittle polyester resin, where similar conditions were modelled, proved the attainability of inter-sonic speed (Rosakis et al., 1999, 2006; Rosakis, 2002).

The question is whether these results, obtained for idealised conditions and homogeneous solids, can be used to verify the attainability of inter-sonic speed in natural heterogeneous rocks. By analogy with mode-I fracture discussed above we can suppose that it is unlikely, due to similar physical reasons: the natural tendency to follow a wavy crack path and unrestricted fracture thickness (unlike the experiments where a straight path and fault thickness of about 10 microns was predetermined). Existing evidence on the attainability of inter-sonic speed in rocks concerns earthquakes only. Earthquakes, however, are associated with another type of shear rupture - general faults - where the inter-sonic speed may result from an entirely different fracture mechanism. This question will be discussed later.

\subsubsection{Two-dimensional fracture development}

Shear fracture is a very complicated structural system that propagates two-dimensionally from a hypocentre forming a fracture plane. Existing models that aim to describe two-dimensional shear fracture propagation consider fractures of an extremely simplified version, without any internal structure. Our understanding of the important question of what kind of natural mechanisms provide two-dimensional shear fracture propagation is presented here.

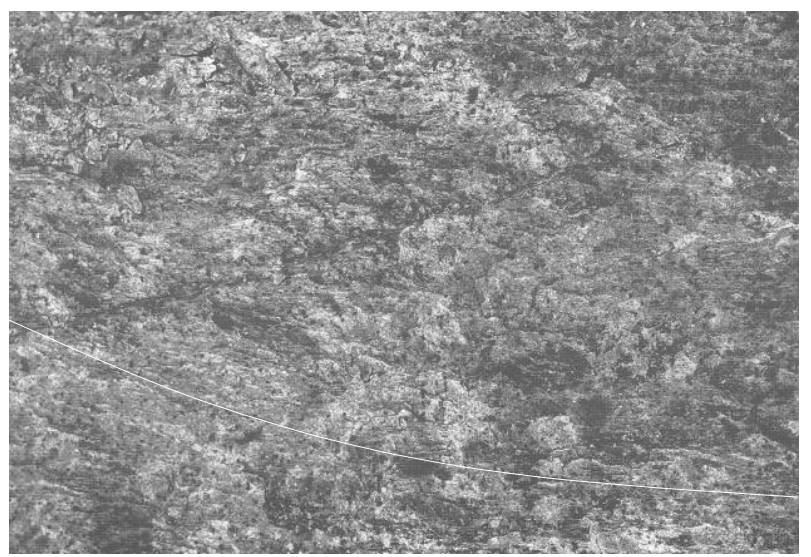

Figure 19 Hackly surface of a shear plane with footprints of rotating blocks (from Ortlepp, 1997) 
Figure 19 shows a lineated hackly surface of a shear fracture initiated in quartzite at a deep mine (depth about $2000 \mathrm{~m}$ ). Ortlepp (1997) points out that the lineated texture is not a result of shear traction as can often be observed on shear surfaces subjected to significant mutual displacement. The hackly surface contains footprints of rotating blocks that filled the shear rupture and have been washed away before the photograph was taken. These blocks are rock chips that look like fish scales. The footprints show that the blocks were arranged in an echelon of rows, and the photograph shows that the rows form curved lines. A white line in the picture reflects the orientation of rows in different areas of the plane.

Taking into account the observed structural features and the fan-shaped nature of the shear fracture propagation, the following two-dimensional model can be reconstructed. Figure 20 shows three stages of the fracture propagation. After the loss of stability at the hypocentre, the fracture, driven by the fan-shaped mechanism, propagates within a plane in all directions. Such propagation is possible due to segmentation of blocks (formation of scales). Dotted ellipses in the picture represent an echelon of rows comprising rock 'scales'. Within the elliptical front of the propagating fracture (shaded area) scales form the fan-shaped structure of the process zone, which propagates as a wave. Cross-sections of this fracture made in any direction should have a structure similar to that shown in Figure 11(f). The distance (or speed) of propagation in different directions is proportional to shear stresses $\tau_{\varphi}$ acting in these directions, as illustrated in Figure 20. Due to the variation of $\tau_{\varphi}$ in different directions, the fracture acquires an ellipsoidal shape. Within a segment $a b c$ the mechanism of fracture formation must be different because in this segment the value of $\tau_{\varphi}$ is too small to provide adequate shear fracture development. We can suppose that in this area fracture development occurs in response to stress redistribution caused by propagation of other parts of the fracture.

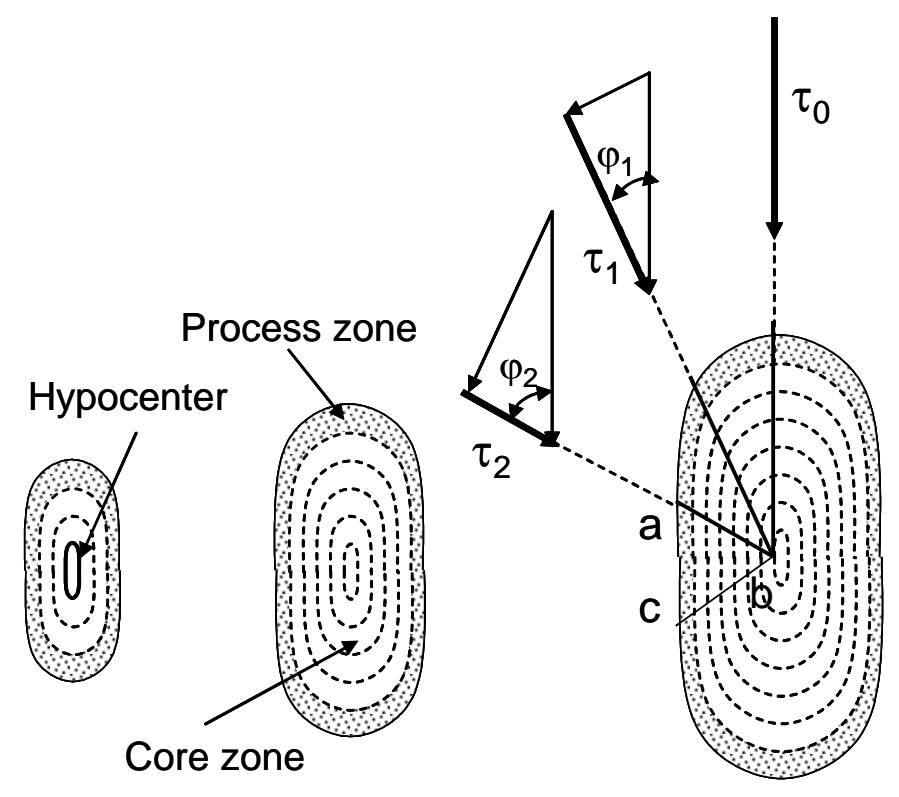

Figure 20 Model of two-dimensional shear fracture development (from Tarasov, 2007)

\subsection{General fault}

General faults - complex discontinuous systems comprising primary fractures, segments, overlap regions, junctions, and other geometrical complexities. The self-equilibrated fan-shaped mechanism acting in primary fractures facilitates fracture propagation due to neutralisation of shear resistance in the fracture tip. The core zone, however, with fully mobilised residual friction and a wavy crack path provides significant resistance to displacement along the fracture. In general faults where large displacements must be accommodated, nature has provided a special mechanism that facilitates this process, decreasing friction along the fault and neutralising the resistance caused by the wavy path. Segmentation is a key element of this mechanism. 


\subsubsection{Fault segmentation (common knowledge)}

Segmentation in the form of discontinuities and branching is a fundamental feature of general faults. Despite very intensive study of the nature of segmentation no consensus of opinion has been reached regarding the physical mechanisms responsible for this phenomenon (Clayton, 1966; Sharp and Clark, 1972; Segall and Pollard, 1983; Granier, 1985; Harris and Day, 1993; Vermilye and Scholz, 1999; Poliakov et al., 2002; Scholz, 2002). Examples of different mechanisms that have been proposed include:

i) Segmentation as result of the linkage of pre-existing segments.

ii) Segments as an echelon of mode-I cracks involved in the structure of a general fault by analogy with tensile cracks in mode-II (or mode III) primary fractures.

iii) Segmentation as a result of separation of a continuous fault when it encounters stronger rock.

iv) Initiation of rupture on a branching fault due to stresses around a dynamically propagating rupture tip located off the main fault plane.

The interaction and linkage between an echelon of fault segments have also been studied extensively (Segall and Pollard, 1980; Sibson, 1986; Burgmann et al., 1994; Scholz, 2002). The role of jogs and overlapping parts of segmented faults in the faulting process was analysed, and it was established, in particular, that all types of jogs represent high strength barriers impeding static and dynamic fault motion (Segal and Pollard, 1980; Sibson, 1985; Harris and Day, 1993; Scholz, 2002).

\subsubsection{New approach - segmentation as a result of advanced fracture triggering}

Analysis of the fault structure in zones linking segments formed in natural conditions and direct observations of the fracture process in laboratory experiments suggest that segmentation is the result of advanced triggering of new fractures due to the stress transfer at some distance ahead of the current fracture. The new fracture propagates bilaterally, both towards the current fracture and in the opposite direction. When the two approaching fractures meet they normally form an overlapping zone. Formation of the overlap is the result of interaction between the stress fields of the approaching fractures.

The geometry of fault zones and its evolutionary trend were experimentally investigated by Otsuki and Dilov (2005) for samples of calcareous siltstone nodule through a repetitive procedure of axial loading. The experiment was conducted at confining pressure of $100 \mathrm{MPa}$. A series of photographs in Figure 21 illustrates the evolution of fault growth. The orientation of the maximum compressive stress $\sigma_{1}$ is denoted by arrows. The fault propagates from left to right. Figure 21(b) reflects the stage at which two embryonic fractures s1 and s2 become distinguishable. Further, they develop propagating in both directions and finally form an overlapping zone with a compression-type fault jog. At this stage a new fracture s3 starts propagating (Figure 21(d)). Figure 21(f) shows the general fault comprising three segments. Important that smaller segment-jog structures are nested in larger segments, forming a hierarchical self-similar fault zone structure.

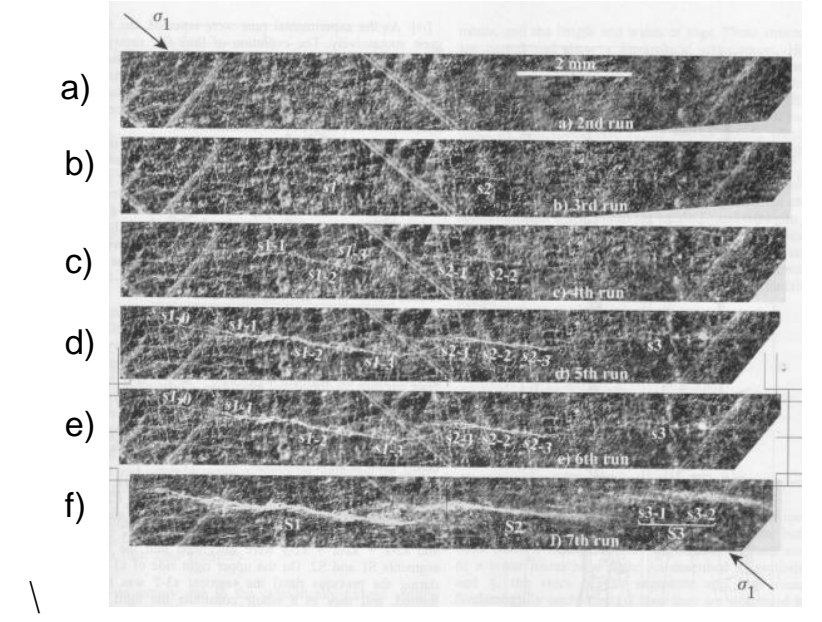

Figure 21 Evolution of segmented fault (from Otsuki and Dilov, 2005) 
Fault triggering has been actively studied in seismology to understand the initiation of new faults. Although the main focus of attention has been the analysis of situations where triggering of new ruptures occurs following some delay after the main event (for example, Harris, 1998; Stain, 1999; King and Cocco, 2000; Ziv and Rubin, 2000; Scholz, 2002) there is evidence suggesting random heterogeneity in the faulting process where a number of sub-events are triggered practically simultaneously within the whole fault zone (Wyss and Brune, 1967; Andrews, 1980; Hanks and McGuire, 1981).

The advanced triggering of new fractures forming segments is a fundamental feature of the general fault propagation for all types of rock and stress conditions. However, hard rocks failed at high confining pressure (or depth) have a very important specific of this process due to activation of the frictionless mechanism at these conditions. The failure process here is spontaneous; propagation of primary fractures is simplified by the fan-shaped mechanism that can make overlap zones very extensive; the overlap zones represent special joining shear fractures comprising rotating blocks and simplifying displacement along the general fault.

\subsubsection{Joining shear fracture}

The two photographs in Figure 22 show examples of joining shear fractures which illustrate different stages of such fracture development. These photographs show fragments of a general fault that caused a large rockburst in a deep South African gold mine. The diagrams between the photographs present each situation schematically. In the picture, the propagating segments are shown by bold arrows while open arrows indicate the directions of shear. The photograph in Figure 22(a) clearly demonstrates that the two approaching segments are represented by primary fractures. The approaching segments propagate along each other forming an overlapping zone. When the overlap reaches some critical length the overlapping zone has separated into rotating blocks by the creation of tensile cracks resulting from shear along the overlapping zone. The photograph in Figure 22(b) shows that an intensive echelon of blocks was eventually formed after further propagation of the segments.

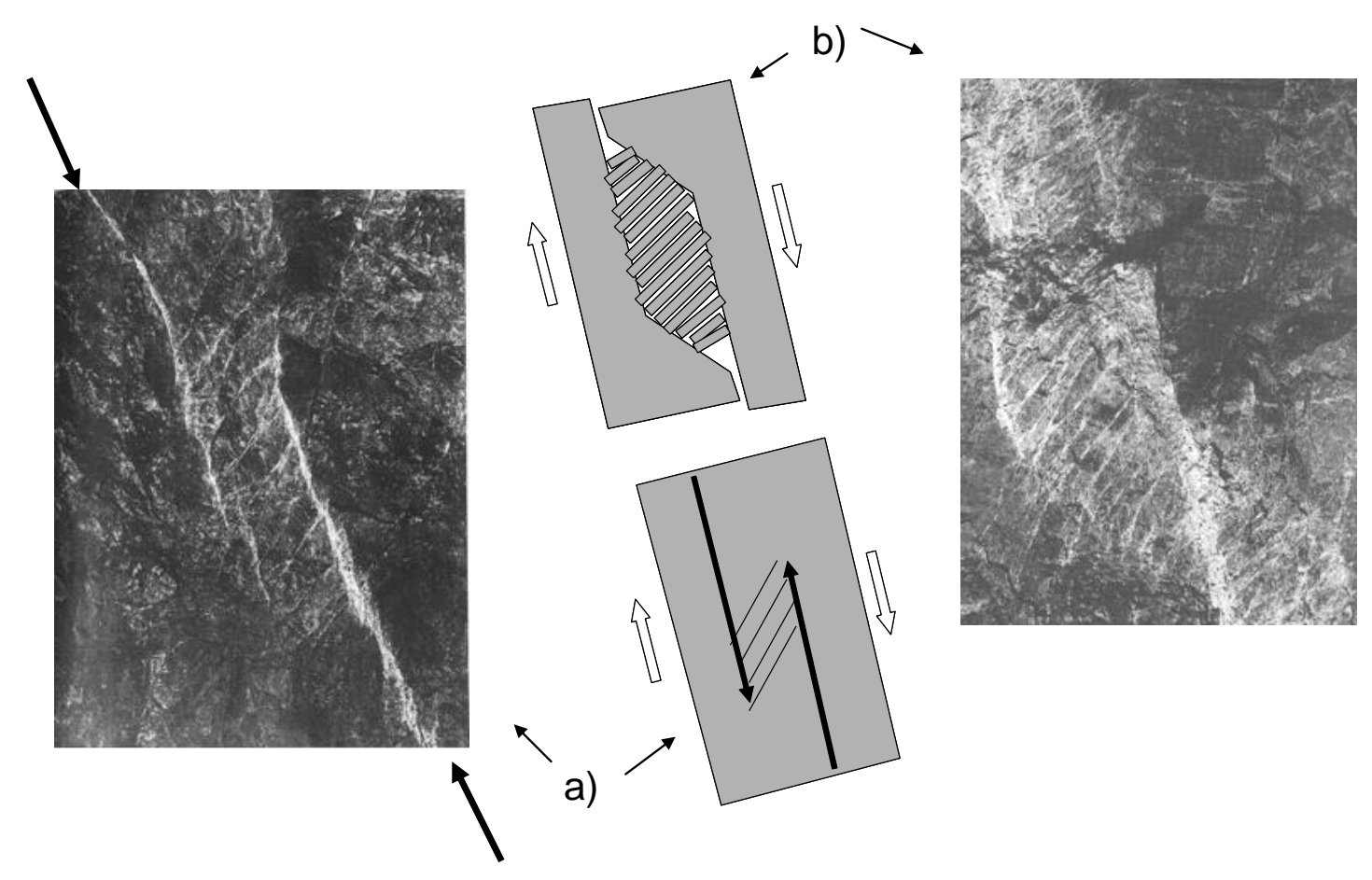

Figure 22 Joining shear fractures formed at the linkage of stepped segments propagating in opposite directions (from Tarasov, 2007; photographs from Ortlepp, 1997) 
Hence, linkage zones between segments represent special joining shear fractures comprising an echelon of rotating blocks, as is typical for all types of shear fractures. Unlike primary shear fractures, which propagate due to the fan-shaped mechanism, the joining fractures are formed simultaneously due to shear within the overlap zone. In contrast with primary fractures, the joining fractures are relatively short and thick. Their function is to facilitate displacement of the general fault due to creation of the block structure with greater block length.

Figure 23 shows three possible types of linkage of stepped segments propagating towards each other. In all cases, the segments are combined in one fault by joining fractures within the linkage zone. All of these fractures comprise block structures where behaviour during displacement of the fault is consistent with the frictionless concept. The existence of joining fractures in the general fault facilitates accommodation of large displacements and decreases the fault resistance to shear. This contrasts with the traditional point of view according to which jogs and other forms of discontinuity represent high resistance barriers impeding static and dynamic fault motion. Joining fractures formed in compression-type fault jogs (left-stepping segments) are of particular interest in this regard. Let us analyse the formation of such joining fractures in more detail.

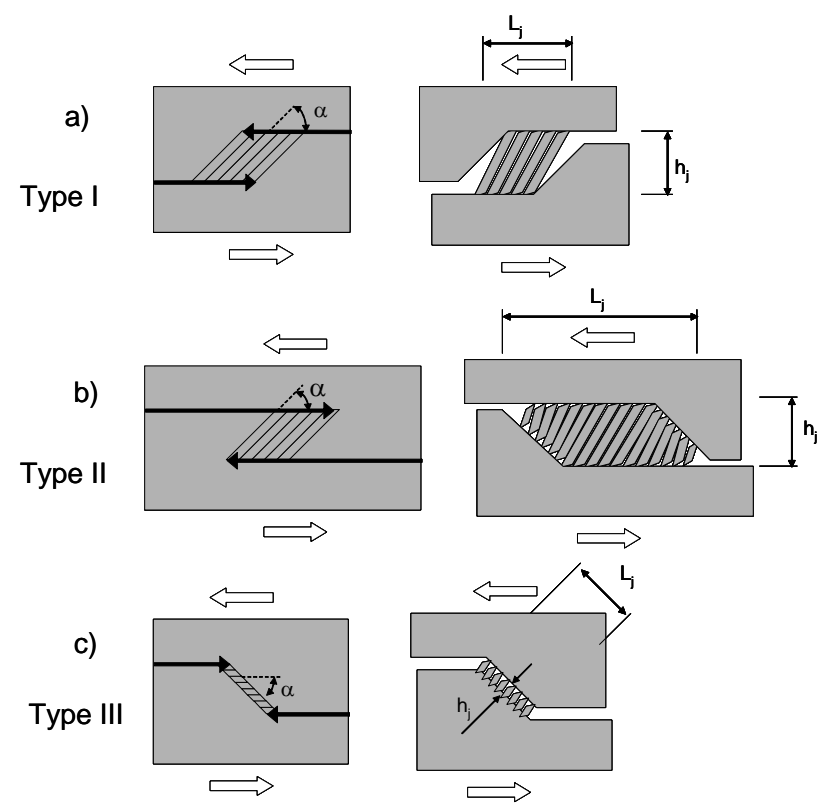

Figure 23 Three possible types of the linkage of stepped segments propagating in opposite directions (from Tarasov, 2007)

\subsubsection{Jump-like fault propagation}

The main "reason" for the creation of joining fractures is the facilitation of shear displacement along the general fault due to a special fault structure comprising rotating blocks. However, joining fractures of "high quality" can be formed only in hard rocks failed at great depth (or high confining pressure). Figure 24 shows the evolution of a general fault comprising an echelon of joining fractures formed on the basis of compression-type jogs. The fault was created spontaneously in quartzite at a depth of $2000 \mathrm{~m}$. The fault propagates upwards from the bottom and involves a number of primary fractures with significantly developed overlap zones. Contours of this fault are shown in the picture by dotted lines with bold arrows representing primary fractures, open arrows indicating the direction of shear and shaded areas representing joining fractures with a corresponding block structure. The orientation of rotating blocks of the fault structure relative to the fault axis is approximately the same in the diagram and in the photograph. Asterisks indicate centres of initiation of advanced triggered fractures. 


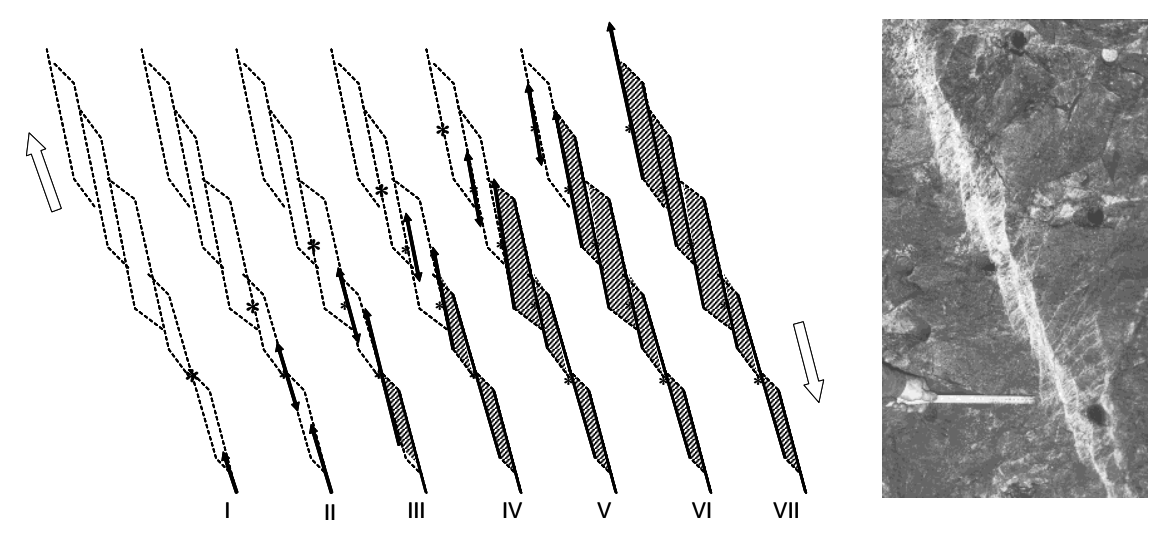

Figure 24 Jump-like fault propagation due to advanced rupture triggering (from Tarasov, 2007; photograph from Ortlepp, 1997)

At stage-I, a dynamically propagating primary fracture triggers an advanced fracture, the further development of which is shown at stage-II. This new fracture (as well as all further triggered fractures) propagates bilaterally towards the current fracture and in the opposite direction. This fracture in turn triggers the next advanced fracture shown at stage-III. At this stage, the length of overlapping zone between the two bottom fractures has reached the critical value and the first joining fracture is created. The process of creating the joining fracture involves dynamic shear accompanied by jump-like displacement within this zone and stress relaxation in the surrounding area. Further fault development occurs through repetition of similar stages. Both processes governing the general fault development - advanced triggering and the formation of joining fractures - have a jump-like character. As a result, joining fractures in combination form practically continuous fault structure consisting of rotating blocks. The fault displacement along this structure will be accompanied by the block rotation which decreases the fault shear resistance in accordance with the frictionless concept. Hence, jump-like propagation for general faults and wave-like (fan-shaped wave) propagation for primary fractures are two different natural forms of shear fracture development.

\subsubsection{Impulse-like energy release}

Figure 25 illustrates different phases of the linkage development between two fractures (segments) propagating toward each other. Figure 25(a) shows a zone of the future collision (quadrangle) and indicates directions of the stress application. Direction of shear stress is shown by open arrows. Figures $25(\mathrm{~b})$ and 25(c) show two situations at different approaching of the fractures. The shear fractures (segments) are represented by solid arrows. The quadrangle here is theoretically divided into two fragments (1 and 2) pressing toward each other by applied stresses. Compressive stress within the linkage zone increases with the segment approach and reaches maximum value (to 1.4 times the background value) when angle $\gamma=60^{\circ}$ (Segall and Pollard, 1980). It should be accentuated that this stress concentration was calculated for static fracture conditions. It is known that stress around a dynamically propagating fracture is a function of the speed of propagation and can be significantly greater compared with the static conditions (Freund, 1990; Broberg, 1999; Poliakov et al., 2002; Rice et al., 2005). We should take into account also the fact that the relative speed of the approaching fractures is double that of the shear rupture speed. In natural conditions for rocks, the reported rupture speed is normally sub-sonic. If we assume the fracture speed to be equal to $1500 \mathrm{~m} / \mathrm{sec}$, the approaching speed is $3000 \mathrm{~m} / \mathrm{sec}$. It means that the compression of the linkage zone is provided with tremendous speed. 

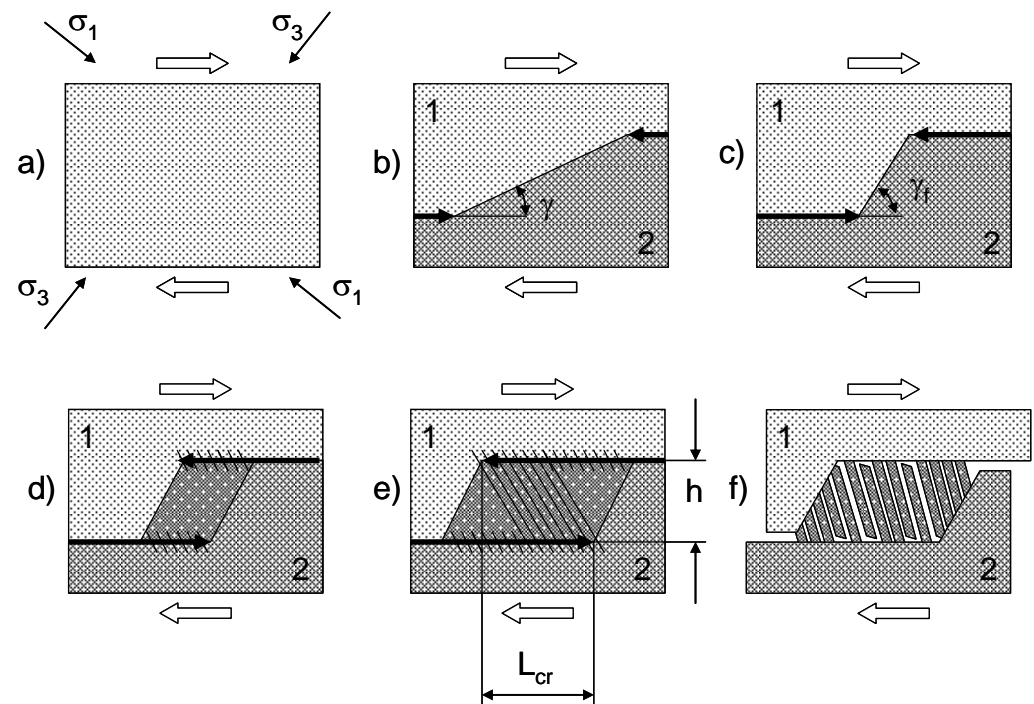

Figure 25 Mechanism of shock-like linkage of left-stepping segments (from Tarasov and Ortlepp, 2007)

At the further propagation of the fractures they confine a zone of overstressed rocks (Figure 25(d)). It is important that, in accordance with the Segall and Pollard (1980) study, the tensile crack formation which can release the stress is suppressed within this zone. The only possibility is the creation of short tensile cracks formed toward the outside of the step (Figure 25(d)). When the extending overlapping zone reaches some critical length $\mathrm{L}_{\mathrm{cr}}$ the nucleus tensile cracks located on the opposite fractures get a chance to be combined (Figure 25(f)). At the formation of joining fracture the accumulated elastic energy is instantly released and tensile cracks within this zone create voids and vacuum.

a)

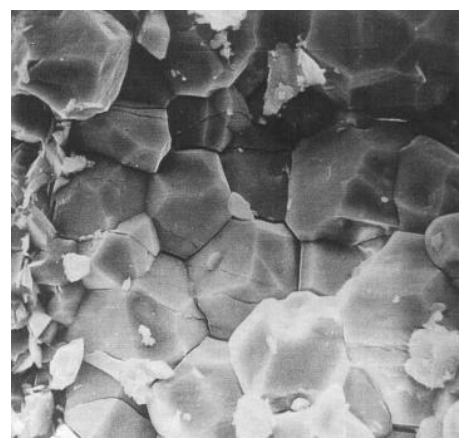

b)

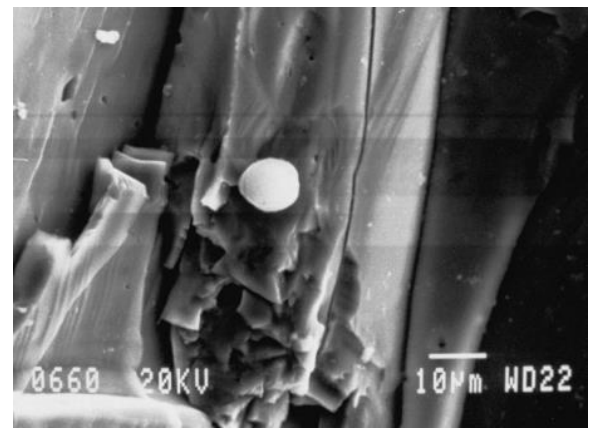

Figure 26 Polyhedral and spherical micro particles formed in joining fractures in quartzite (from Ortlepp, 1992, 2005)

The presence of two types of micro-particles (polyhedral and spherical) of very different genesis within the rupture zone in quartzite at depth of $2000 \mathrm{~m}$ is a specific manifestation of extraordinary conditions taking place at spontaneous rupture formation (see Figure 26). The particles were found and studied by Ortlepp (1992, 1999, 2001) and Ortlepp et al. (2005). The intriguing fact is that polyhedral sub-particles (Figure 26(a)) are formed due to fragmentation of a quartz grain into elemental sub-particles having remarkable uniformity in size and the near-perfect crystal-like shape. Such particle geometry gives reason to suppose that the most plausible explanation of their formation is shock loading/unloading taking place in the fracture zone.

The geometry of another sort of particles is spherical (Figure 26(b)). Ortlepp pointed out that these particles are the preserved evidence of an extraordinary micro-phenomenon that entails some relatively low melting 
point silicate mineral melting, vapourising, condensing into minute droplets and freezing all in a few milliseconds.

The rupture mechanism illustrated in Figure 25 can provide conditions for the formation of the both types of particles. It is the source of momentary accumulation and dissipation of tremendous amount of energy. The shock compression of relatively small volume of rock at extremely high speed of the blow application $(3000 \mathrm{~m} / \mathrm{sec})$ can cause momentary temperature elevation. The following failure with the momentary creation of void within the initially solid material should produce high vacuum.

\subsubsection{Speed trebling mechanism}

The average rupture speeds for most shallow crustal earthquakes range from 0.75 to $0.95 c_{R}$ where $c_{R}$ is the average Rayleigh wave speed in the surrounding crustal rock mass (Rosakis, 2002). However, considerable evidence of intersonic rupture speeds have been reported (Archuleta, 1982; Olsen et al., 1997; Ellsworth and Celebi, 1999; Hernandez et al., 1999). It is important to emphasise that earthquake ruptures represent general faults in our classification. Rock damage associated with general faults compared with primary fractures is significantly greater. In this regard it appears paradoxical that intersonic speed is attainable for earthquake ruptures and has never been reported for primary fractures in rocks. This paradox can be explained if we analyse the mechanism of advanced triggering in more detail. The mechanism leads to a propagation speed for general faults that is three times that in primary fractures. Figure 27 illustrates this.

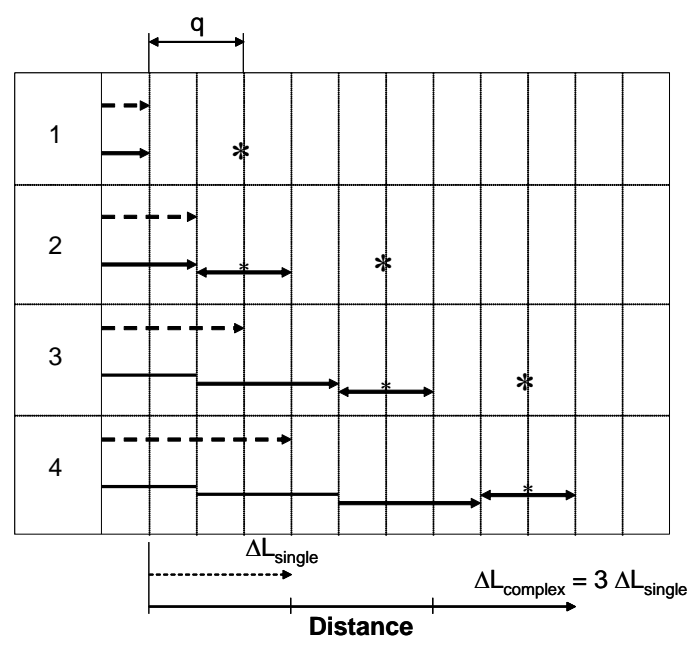

Figure 27 Illustration of the speed trebling mechanism (from Tarasov, 2007)

The figure shows four stages of propagation of two different faults, which propagate from left to right (the horizontal axis representing distance). The first fault shown by dotted arrows develops as a primary fracture. Solid arrows represent the general fault propagating in accordance with the advanced triggering mechanism, with centres of triggered segments shown by asterisks. It is assumed that the speed of propagation of primary fractures in the general fault and in the first fault is the same. The total growth for the two modes of fault propagation, over the four stages considered, is indicated at the bottom of the figure, showing that the growth provided by the new mechanism is three times that for the conventional mode $\left(\Delta L_{\text {complex }}=3 \Delta L_{\text {single }}\right)$. In this example, the distance $q$ between the fault edge and each new nucleation centre in the next segment was kept the same. It should be noted that the efficiency of the trebling mechanism does not depend on the value of $q$. However, we can expect that with the fault growth the distance $q$ should increase due to increasing influence of the growing fault on the stress regime in the surrounding rock mass.

Before making a final conclusion about the general fault speed, it is important to mention the following result of observations. It was found by Wyss and Brune (1967) that the 1964 Alaska earthquake, propagated from east to west at a speed near the shear velocity, and consisted of a sequence of recognisable sub-events. The observed feature confirms that the nature of general fault propagation involves advanced triggering and the inter-sonic speed achievement is a result of the trebling effect. Hence, to reach a speed of $5 \mathrm{~km} / \mathrm{s}$ the speed of primary fractures should be about $1.7 \mathrm{~km} / \mathrm{s}$. The result obtained looks realistic and explains the 
paradoxical combination of inter-sonic speed and severe damage of the rock mass within the fault zone which have been observed in earthquake ruptures.

\subsubsection{Two-dimensional model}

Figure 28(a) illustrates the development of a general fault, initiated from a hypocentre shown by the asterisk. Due to stress transfer a set of new faults can be triggered in the vicinity of the first fault. Once this occurs, the influence of the combined fault on the surrounding rockmass increases, which could trigger new faults at greater distances. It should be noted that the triggered segments develop on the same principle of advanced triggering creating a self-similar structural hierarchy (see Figure 28(b)). This mechanism is therefore consistent with the fractal structure observed in natural faults at all scales and in laboratory conditions (Scholz, 2002; Otsudi and Dilov, 2005). Figure 28 shows symmetric location of segments in the general fault, although in reality this picture may be very chaotic. However, the main concept of its formation stays the same: the larger the fault grows, the greater the chance to trigger new faults at greater distance; also the greater the distance, the larger the new activated segment. So, dimensions of segments increase with fault development from hypocentre to periphery. Although chaotic in detail, the fault structure in general should be similar to that presented in Figure 28. When such complex fault reaches an open surface (axes $x-x$ or $y-y$ in Figure 28) its cross-section can be seen as an echelon of identical segments.

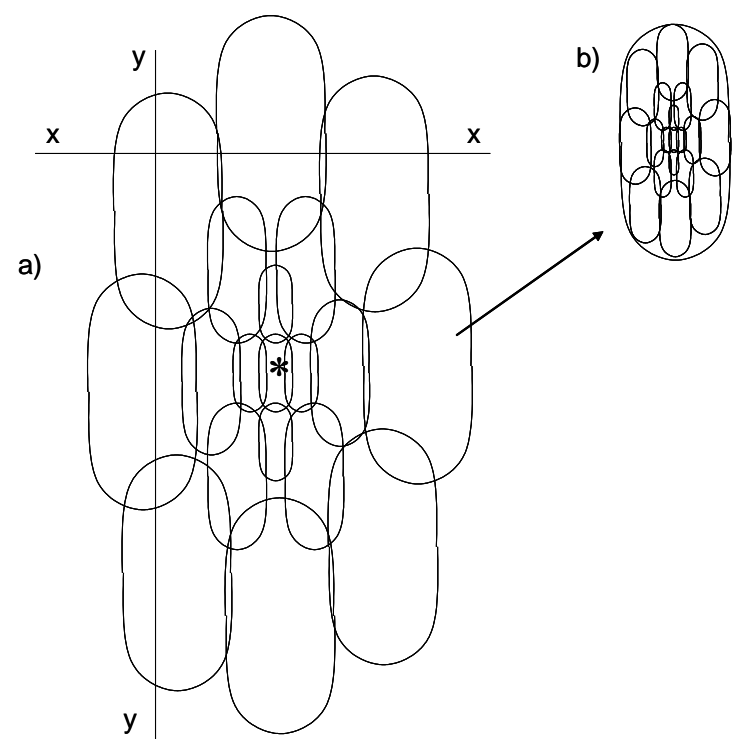

Figure 28 Two-dimensional model of the general fault formation (from Tarasov, 2007)

It should be emphasised again that areas of linkage between segments where joining shear fractures are formed facilitate fault displacement and can significantly reduce the fault strength due to activation of the frictionless mechanism in these fractures. The larger the proportion of linkage areas in the total fault plane, the greater the influence of the frictionless mechanism on the fault resistance. Figure 28 shows that in some zones of the fault, three or even four segments can intersect creating very complicated junctions. It should also be noted that Figure 28 illustrates the direct sequence of the general fault propagation, which is characterised by an increase in the segment size from the hypocentre to periphery. However, it is clear, and field observations verify this (Scholz, 2002), that the maximum fault displacement will be accumulated in the central part of the fault. This means that with further fault propagation additional fracture processes will be activated leading to significant and increasing damage of the central part of the fault.

\section{Fault reactivation}

It has been established that an earthquake source is a shear dislocation on the fault plane, and major earthquakes occur repeatedly along the same pre-existing faults. Stick-slip instability as a mechanism for crustal earthquake failure is generally accepted because stick-slip behaviour could account for the episodic 
occurrence of earthquakes on faults characterised by stress drops which are low compared to the strength of intact rock. After this hypothesis was proposed by Brace and Byerlee in 1966, intensive and comprehensive studies of stick-slip instability in rocks have been undertaken. Two different stick-slip mechanisms are accepted at present as most plausible for explanation of instability on real faults: i) a mechanism of brittle instability and ii) a mechanism based on velocity weakening and healing effects (Byerlee, 1969; Dieterich, 1972; Ruina, 1983; Ohnaka et al., 1986; Tullis, 1988; Scholz, 2002). High heterogeneity of fault properties and its effect on the source processes have been recognised (Wald and Heaton, 1994; Ide et al., 1996; $\mathrm{Wu}$ et al., 2001). It is shown that seismic nucleation is intimately related to the heterogeneous frictional properties of fault planes (Umeda, 1990; Ellsworth and Beroza, 1995). Das and Aki (1977) demonstrated first how the complexity of earthquake source processes and seismic radiations can be reproduced by "barrier model" of a fault plane.

It is important that all existing models are based on frictional approach and consider simplified fault structures: asperity contacts and structure-less comminuted gauge. However, real faults formed in hard rocks at conditions of high minor stress comprise a specific structure consisting of an echelon of rotating blocks. The frictionless approach gives ground to suppose that such structure should influence the fault strength and its instability. This question is discussed shortly (Tarasov, 2008). In accordance with the analysis conducted in the previous paragraphs general faults comprise two types of basic fractures (primary and joining) of very different thickness. Despite the fact that any shear rupture involved in the general fault consists of the same structure - an echelon of rotating blocks - stages of the block rogation in them can be very different. The block orientation in turn determines the structure resistance to shear (see Figure 3).

All primary fractures involved in the general fault should have normal frictional resistance because their structure consists of blocks completed their rotation. In contrast to the primary fractures, joining fractures can have very different shear resistance (positive and negative) due to different stages of the block rotation in them. Different angles of the block orientation in different joining fractures can be caused in particular by the difference of their thickness. Thus, general faults are extremely heterogeneous formations in respect of shear resistance. Shear displacement along such fault should be accompanied by further rotation of the blocks and by corresponding variation in shear resistance, which can cause both local and total fault instability.

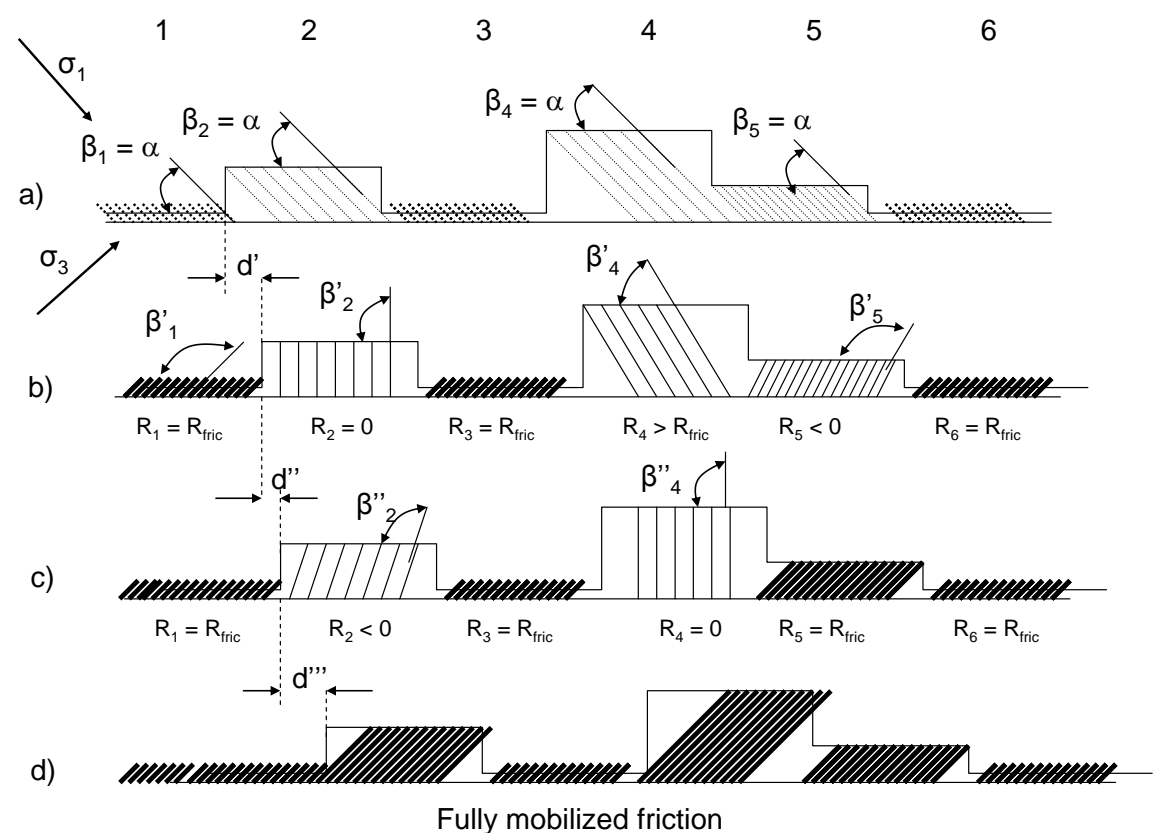

Figure 29 Features of the block rotation in general faults characterised by high variation in the fault thickness (from Tarasov, 2008)

Figure 29 illustrates principles of variation of the structure condition in a simplified general fault at different stages of its development. The fault consists of a number of fragments of different thickness. Figure 29(a) shows the fault before failure with its potential block structure. For simplicity, we assume that the initial 
angle of block orientation in all fragments is the same (along the major stress $\left(\sigma_{1}\right)$ ) and that the upper face of the fault moves to the right, while the bottom one stays stable. Figure 29(b) shows the fault just after the spontaneous failure. The total system "fault structure-surrounding rock mass" after the displacement has come into an equilibrium condition. Let us suppose that the displacement along the fault was uniform and equal to d'. Due to different thickness of the fault fragments blocks in them rotated on different angles. In thin fragments blocks completed their rotation make the shear resistance in these areas equal to frictional one. Such blocks are shown in the figure by thick lines. Other fragments depending on the block orientation can have both positive and negative shear resistance $R$ (e.g. for fragment $-2 R_{2}=0$; for fragment- 4 the resistance is positive and can be greater than frictional one $R_{4}>R_{\text {frictional }}$; for fragment-5 $R_{5}<0$ ). Depending on the proportion between areas with the different resistance the average (total) fault resistance can be above, equal to, and lower than the frictional resistance. The significant variation in shear resistance along the fault should cause similar stress variation in surrounding rock mass. On the boundaries between the fragments the stress situation should be more complicated. Thus, the fault structure consisting of an echelon of rotating blocks at different stages of their rotation creates very high stress heterogeneity along the fault.

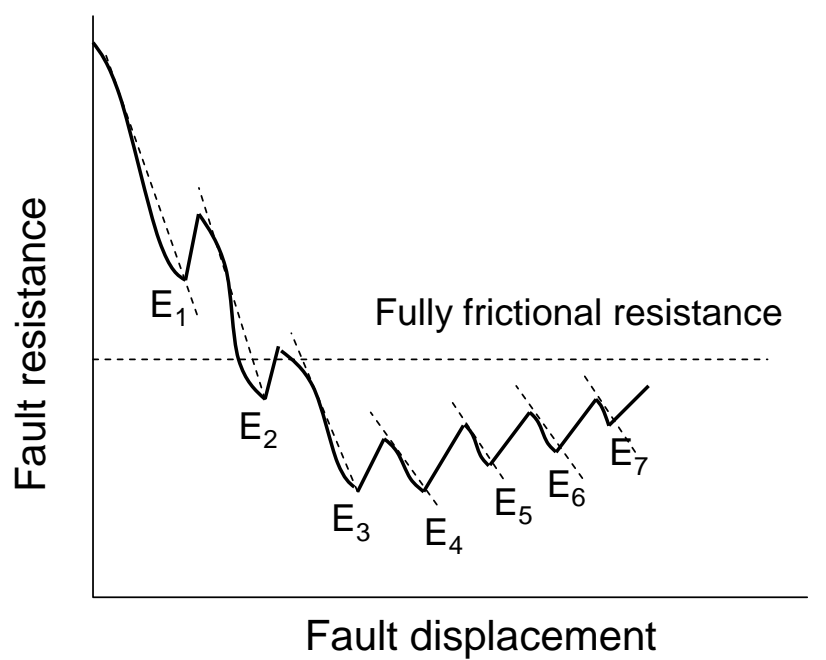

Figure 30 Fluctuation of shear resistance of the general fault at its displacement caused by sequential activation of the frictionless mechanism in different fault zones (from Tarasov, 2008)

Further displacement along the fault should be accompanied by very irregular variations in local stress and local displacement in response to the block rotation. This can cause local and total fault instability as well as irregular distribution of stress drop and slip along the fault during the instability. Figure 30 illustrates symbolically fluctuations of average (total) fault resistance with displacement. The periodic sharp decrease in fault resistance here associates with the frictionless mechanism activation in some fault fragments, while the following increase in fault resistance associates with the friction restoration in them. The stress drop stages can be unstable if the loading conditions are insufficiently stiff. Inclined dotted lines in the figure represent stiffness of the surrounding medium. Points E correspond to equilibrium conditions after each event of instability.

It should be emphasised that this mechanism can provide the combination of such features observed in natural faults as: very low fault strength (lower the frictional level) and periodical stick-slip instability. However, with displacement the proportion of areas with restored friction should increase (black zones in Figure 29) the average fault resistance to the frictional level. Eventually the discussed stick-slip mechanism based on the frictionless concept should be suppressed.

\section{Conclusions}

This paper proposes a new "frictionless concept" which explains a number of paradoxes and unexplained phenomena associated with the shear rupture process. It is shown, in particular, that hard rocks at high confining pressure acquire specific properties which distinguish them markedly from common rock 
behaviour - they become extremely brittle and lose shear resistance within a certain range of the shear rupture displacement. The combination of these properties increases instability with depth and makes rupture abnormally violent. These hard rock features are caused by the intrinsic nature of the fault structure which is an echelon of blocks operating as hinges, essentially eliminating friction at high confining pressure.

The frictionless concept allows the process of shear fracture development to be viewed from a new point of view. A simple but well-founded classification of shear fractures is used in the paper, namely: primary and joining fractures. It is shown that despite the similarity in their structures each of which is represented by an echelon of rotating blocks, the development of these two forms of fractures is drastically different. The primary fractures propagate in a wave-like manner due to a fan-shaped self-equilibrated mechanism created on the basis of rotating blocks. The joining fractures are the result of a jump-like manner of the fault propagation due to advanced triggering mechanism. Features of the both mechanisms have been analysed in the paper allowing a number of paradoxical observations associated with shear fracture development to be explained. Two-dimensional models for both types of fracture have also been presented.

The paper proposes a new mechanism of stick-slip instability based on the frictionless concept. It is shown that the structure of rotating blocks in pre-existing faults can cause stick-slip instability due to very unstable behaviour of this structure at the fault displacement.

\section{Acknowledgements}

This work was supported during a number of years by the Australian Special Research Centre for Offshore Foundation Systems (COFS). This support is gratefully acknowledged. The author expresses his sincere gratitude to the founding Director of COFS, Professor Mark Randolph, for helpful discussion and support of this work at all stages of its development.

\section{References}

Andrews, D. (1976) Rupture velocity of plane strain shear cracks, J. Geophys, Res. 81, pp. 5679-5687.

Andrews, D. (1980) A stochastic fault model, static case. J. Geophys. Res. 85, pp. 3867-3887.

Archuleta, R. (1982) Analysis of near source static and dynamic measurements from the 1979 Imperial Valley earthquake, Bull. Seismol. Soc. Am., 72, pp. 1927-1956.

Ashby, M.F. and Sammis, C.G. (1990) The damage mechanics of brittle solids in compression, Pure Appl. Geophys., 133, pp. 489-521.

Bowden, F.P. and Tabor, D. (1964) The friction and lubrication of solids. Vol. 2, Clarendon, Oxford.

Brace, W.F. and Byerlee, J.D. (1966) Stick-slip as a mechanism for earthquakes. Science, 153, pp. 990-992.

Broberg, K.B. (1999) Cracks and Fracture, London: Academic.

Burgmann, R., Pollard, D.D. and Martel, S.J. (1994) Slip distributions on faults: effects of stress gradients, inelastic deformation, heterogeneous host-rock stiffness, and fault interaction, J. Struct. Geol. 16, pp. 1675-1690.

Byerlee, J.D. (1969) The mechanics of stick-slip. Tectonophysics, pp. 475-486.

Chester, F.M., Evans, J.P. and Biegel, R.L. (1993) Internal structure and weakening mechanisms of the San Andreas Fault, J. Geophys. Res., 98, pp. 771-786.

Clayton, L. (1966) Tectonic depressions along the Hase fault, a transcurrent fault in north Canterbury, New Zealand, N. Z. J. Geol. Geophys. 9, pp. 94-104.

Cox, S.J.D. and Scholz, C.H. (1988) On the formation and growth of faults: an experimental study. J. Struct. Geol., 10, pp. 413-430.

Das, S. (1985) Application of dynamic shear crack models to the study of the earthquake faulting process. Int. J. Fract., 27, pp. 263-276.

Das, S. and Aki, K. (1977) Fault plane with barriers: A versatile earthquake model. J. Geophys. Res., 103, pp. 21091-21097.

Dieterich, J.H. (1972) Time-dependent friction in rocks. J. Geophys. Res. 77, pp. 3690-3697.

Domowska, R. and Rice, J.R. (1986) Continuum theories in solid earth physics, Amsterdam: Elsevier, pp. 1881-1902.

Ellsworth, W.L. and Beroza, G.C. (1995) Seismic evidence for an earthquake nucleation phase. Science, 268, pp. 851-855.

Ellsworth, W.L. and Celebi, M. (1999) Near field displacement time histories of the M7.4 Kocaeli (Izmit) Turkey earthquake of 17 August 1999, The American Geophysical union Fall meeting. Vol. 80 (Washington DC: American Geophysical Union), p. F648.

Freund, L.B. (1990) Dynamic fracture mechanics, Cambridge: Cambridge University Press. 
Gao, H. (1993) Surface roughening and branching instabilities in dynamic fracture. J. Mech. Phys. Solids., 41, N3, pp. $457-486$.

Granier, T. (1985) Origin, damping and pattern of development of faults in granite, Tectonics, 4, pp. $721-737$.

Hanks, T. and McGuire, R. (1981) The character of high-frequency strong ground motion. Bull. Seismol. Soc. Am. 71, pp. 2071-2095.

Harris, R.A. and Day, S.M. (1993) Dynamics of fault interaction: parallel strike-slip faults. J. Geophys. Res., 98, pp. 4461-4472.

Harris, R.A. (1998) Introduction to special section: Stress triggers, stress shadows, and implications for seismic hazard, J. Geophys. Res.-Solid Earth., 103, pp. 24347-24358.

Hernandez, B., Cotton, F. and Campillo, M. (1999) Contribution of Radar interferometry to a two-step inversion of the kinematic process of the 1992 Landers earthquake. J. Geophys. Res. 104, pp. 13083-13099.

Hickman, S.H. (1991) Stress in the lithosphere and the strength of active faults, Rev. Geophys, 29, pp. 759-775.

Horii, H. and Nemat-Nasser, S. (1985) Compression-induced microcrack growth in brittle solids: Axial splitting and shear failure, J. Geophys. Res., 90, pp. 3105-3125.

Ida, Y. (1982) Stress concentration and unsteady propagation of longitudinal shear cracks, J. Geophys. Res., 77, pp. 3796-385.

Ide, S., Takeo, M. and Yoshida, Y. (1996) Source process of the 1995 Kobe earthquake: Determination of spatiotemporal slip distribution by Bayesian modelling. Bull. Seismol. Soc. Am., 86, pp. 547-566.

Johnson, E. (1992) Process region changes for rapidly propagating cracks. Int. J. Fract., 55, pp. 47-63.

Johnson, T., Wu, F.T. and Scholz, C.H. (1973) Source parameters for stick-slip and for earthquakes. Science 179, pp. 278-280.

Kanamori, H. and Brodsky, E. (2001) The physics of earthquakes, Phys. Today, 54, pp. 34-40.

King, G.C.P. and Sammis, C.G. (1992) The mechanisms of finite brittle strain, PAGEOPH, 138, pp. 611-639.

King, G.C.P. and Cocco, M. (2000) Fault interaction by elastic stress changes; new clues from earthquake sequences, Advances in Geophys. 44, pp. 1-38.

Lawn, B.R. and Wilshaw, T.R. (1975) Fracture of Brittle Solids New York: Cambridge University Press.

Lockner, D.A., Byerlee, J.D., Kuksenko, V., Ponomarev, A. and Sidorin, A. (1991) Quasi-static fault growth and shear fracture energy in granite Nature, 350, pp. 39-42.

Mandel, G. (2000) Faulting in brittle rocks, Springer-Verlag Berlin Heidelberg.

McKenzie, D. and Brune, N. (1972) Melting on fault planes during large earthquakes, Geophys. J.R. Astr. Soc., 29, pp. 65-78.

Moore, D.E., Summers, R. and Byerlee, J.D. (1990) Faults, fractures and other deformation features produced during loading of granite in triaxial equipment. U.S. Geol. Surv. Open File Rep., pp. 90-349.

Moore, D.E. and Lockner, D.A. (1995) The role of microcracking in shear-fracture propagation in granite, J. Struct. Geol. 17, pp. 95-114.

Nur, A. (1978) Nonuniform friction as a basis for earthquake mechanics. Pageoph, 116, pp. 964-989.

Ohnaka, M. (1973) Experimental studies of stick-slip and their application to the earthquake source mechanism. J. Phys. Earth 21, pp. 285-303.

Ohnaka, M., Kuwahara, Y., Yamamoto, K. and Hirasawa, T. (1986) Dynamic breakdown processes and the generating mechanism for high-frequency elastic radiation during stick-slip instabilities. In Earthquake source mechanics Geophys Monogr Ser, Edited by Das S, Boatwright J, Scholz CH. 13-24, AGU, Washington DC.

Ohnaka, M. and Kuwahara, Y. (1990) Characteristic features of local breakdown near a crack-tip in the transition zone from nucleation to unstable rupture during stick-slip shear failure, Tectonophysics 175, pp. 197-220.

Olsen, K.B., Madariaga, R. and Archuleta, R.J. (1997) Three-dimensional dynamic simulation of the 1992 Landers earthquake, Science, 278, 834.

Ortlepp, W.D. (1992) Note on fault-slip motion inferred from a study of micro-cataclastic particles from an underground shear rupture. PAGEOPH. Vol. 139, No. 3/4, pp. 677-695.

Ortlepp, W.D. (1997) Rock fracture and rockbursts. The South African Institute of Mining and Metallurgy, Johannesburg.

Ortlepp, W.D. (1999) Observation of mining-induced faults in an intact rock mass at depth. Int. J. Rock Mech., 37 , pp. 423-436.

Ortlepp, W.D. (2000) Observation of mining-induced faults in an intact rock mass at depth. Int. J. Rock Mech. Min. Sc., 37 , pp. 423-436.

Ortlepp, W.D. (2001) Thoughts on the rockburst source mechanism based on observations of the mine-induced shear rupture. The 5th International Symposium on Rockburst and Seismicity in Mines (RaSiM5), Johannesburg, South Africa, pp. 43-51.

Ortlepp, W.D., Armstrong, R., Ryder, J.A. and O'Connor, D. (2005) Fundamental study of micro-fracturing on the slipsurface of mine-induced dynamic brittle shear zones. Sixth International Symposium on Rockburst and Seismicity in Mines Proceedings, Perth, Australia, March, 2005. 
Otsuki, K. and Dilov, T. (2005) Evolution of hierarchical self-similar geometry of experimental fault zones: Implications for seismic nucleation and earthquake size. J. Geoph. Res. 110, B03303, doi:10.1029/2004JB003359.

Peng, S. and Johnson, A.M. (1972) Crack growth and faulting in cylindrical specimens of Chelmsford granite. Int. J. Rock Mech. Min. Sci. 9, pp. 37-86.

Pollard, D.D. and Segall, P. (1987) Theoretical displacements and stresses near fractures in rock with applications to faults, joints, veins, dikes, and solution surfaces. In: Fracture Mechanics of Rock, BK Atkinson, ed. San Diego, Calif: Academic, pp. 277-349.

Poliakov, A.N.B., Domowska, R. and Rice, J.R. (2002) Dynamic shear rupture interactions with fault bends and offaxis secondary faulting, J. Geophys. Res. 107, no. B11, 2295, doi 10.1029/2001JB000572, ESE 6-1-6-18.

Ravi-Chandar, K. and Knauss, W.G. (1984) An experimental investigation into dynamic fracture: I. Crack initiation and arrest. Int. J. Fract., 25, pp. 247-262.

Reches, Z. and Lockner, D.A. (1994) Nucleation and growth of faults in brittle rocks. J. Geophys. Res. Vol. 99, No. B9, pp. 18159-18173.

Rice, J.R. (2001) New perspectives on crack and fault dynamics in Mechanics for a New Millennium: The 20th International congress of theoretical and applied mechanics, edited by H. Aref and J.W. Phillips (Dordrecht: Kluwer), pp. 1-23.

Rice, J.R., Sammis, C.G. and Parsons, R. (2005) Off-fault secondary failure indicud by a dynamic slip pulse. Bull. Seismol. Soc. Am. 95, No. 1. pp. 109-134.

Rosakis, A.J., Samudrala, O. and Coker, D. (1999) Cracks faster than the shear wave speed. Science, 284, pp. 1337-1340.

Rosakis, A.J. (2002) Intersonic shear cracks and fault ruptures. Advances in physics, Vol. 51, No. 4, pp. $1189-1257$.

Rosakis, A.J. (2006) Laboratory earthquakes, Int. J. Fracture, 138, pp. 211-218.

Ruina, A. (1983) Slip instability and state variable friction laws. J. Geophys Res. 88, pp. 10359-10370.

Scholz, C.H. (2002) The mechanics of earthquakes and faulting. Cambridge University Press.

Segall, P. and Pollard, D.D. (1980) The mechanics of discontinuous faults, J. Geophys. Res., 85, pp. 4337-4250.

Segall, P. and Pollard, D.D. (1983) Nucleation and growth of strike-slip faults in granite, J. Geoph. Res., 88, pp. 555-568.

Sharp, R.V. and Clark, M.M. (1972) Geologic evidence of previous faulting near the 1968 rupture on the Coyote Creed fault, U.S. Geol. Surv. Proof. Pap., 787, pp. 131-140.

Sibson, R.H. (1980) Power dissipation and stress levels on faults in the upper crust. J. Geophys. Res., 85, pp. 6239-6247.

Sibson, R.H. (1985) Stopping of earthquake ruptures at dilatational jogs. Nature, 316, pp. 248-251.

Sibson, R.H. (1986) Rupture interaction with fault jogs, Earthquake source mechanisms, S. Das, J. Boatwright and C.H. Scholz (editors), American Geophysical Union, Washington.

Stain, R.S. (1999) The role of stress transfer in earthquake occurrence. Nature, 402, pp. 605-609.

Tarasov, B.G. (2007) Intersonic shear rupture mechanism. Int. J. Rock Mech. Min. Sci. 45, 6, pp. 914-928.

Tarasov, B.G. and Randolph, M.F. (2007) Frictionless shear at great depth and other paradoxes of hard rocks, Int. J. Rock Mech. Min. Sci. 45, 3, pp. 316-328.

Tarasov, B.G. (2008) Brittle stick-slip instability and fault reactivation (submitted to Int. J. Rock Mech. Min. Sci. on 26. 03. 2008)

Tse, S. and Rice, J. (1986) Crustal earthquake instability in relation to the depth variation of frictional slip properties. J. Geophys. Res. 91, pp. 9452-9472.

Tullis, T.E. (1988) Rock friction constitutive behaviour from laboratory experiments and its implications for an earthquake prediction field monitoring program. Pure Appl. Geophys 126, pp. 555-558.

Umeda, Y. (1990) High-amplitude seismic waves radiated from the bright spot of an earthquake. Tectonophysics, 175, pp. 81-92.

Vermilye, J.M. and Scholz, C.H. (1999) Fault propagation and segmentation: insight from the microstructural examination of a small fault, J. Struct. Geol., 21, pp. 1623-1636.

Wald, D.J. and Heaton, T.H. (1994) Temporal distribution of slip for the 1992 Landers, California, earthquake. Bull. Seismol. Soc. Am. 84, pp. 668-691.

Washabaugh, P.D. and Knauss, W.G. (1994) A reconciliation of dynamic crack velocity and Rayleigh wave speed in isotropic brittle solids. Int. J. Fract., 65, pp. 97-114.

Wu, F.T., Thomson, K.C. and Kuenzler, H. (1972) Stick-slip propagation velocity and seismic source mechanism. Bull. Seismol. Soc. Am. 62, pp. 1621-1628.

Wu, C.J., Takeo, M. and Ide, S. (2001) Source process of the Chi-Chi earthquake: A joint inversion of strong motion data and global positioning system data with a multifault model. Bull. Seismol. Soc. Am., 91, pp. 1128-1143.

Wyss, M. and Brune, J. (1967) The Alaska earthquake of 28 March 1964: A complex multiple rupture, Bull. Seismol. Soc. Am., 57, pp. 1017-1023. 
Ziv, A. and Rubin, A.M. (2000) Static stress transfer and earthquake triggering: no lower threshold in sight, J. Geophys. Res., 105, pp. 13631-13642. 